University of Rhode Island

DigitalCommons@URI

Open Access Master's Theses

2020

\title{
EFFECTS OF LONG TERM DEEP-SEA IMMERSION ON THE MECHANICAL RESPONSE OF COMPOSITE STRUCTURES
}

Dillon T. Fontaine

University of Rhode Island, dtf96fontaine@aol.com

Follow this and additional works at: https://digitalcommons.uri.edu/theses

\section{Recommended Citation}

Fontaine, Dillon T., "EFFECTS OF LONG TERM DEEP-SEA IMMERSION ON THE MECHANICAL RESPONSE OF COMPOSITE STRUCTURES" (2020). Open Access Master's Theses. Paper 1863.

https://digitalcommons.uri.edu/theses/1863

This Thesis is brought to you for free and open access by DigitalCommons@URI. It has been accepted for inclusion in Open Access Master's Theses by an authorized administrator of DigitalCommons@URI. For more information, please contact digitalcommons-group@uri.edu. 
EFFECTS OF LONG TERM DEEP-SEA IMMERSION ON THE MECHANICAL RESPONSE OF COMPOSITE STRUCTURES

BY

DILLON T. FONTAINE

A THESIS SUBMITTED IN PARTIAL FULFILLMENT OF THE REQUIREMENTS FOR THE DEGREE OF MASTER OF SCIENCE

IN

MECHANICAL ENGINEERING AND APPLIED MECHANICS

UNIVERSITY OF RHODE ISLAND

2020 


\section{MASTER OF SCIENCE THESIS}

$\mathrm{OF}$

DILLON T. FONTAINE

\section{APPROVED:}

Thesis Committee:

Major Professor $\quad$ Arun Shukla
DML Meyer
Gopu Potty
James M. LeBlanc
Nasser H. Zawia
DEAN OF THE GRADUATE SCHOOL

UNIVERSITY OF RHODE ISLAND

2020 


\begin{abstract}
The effects of long term exposure to a sea-floor depth ocean environment on the mechanical behavior of carbon-fiber / epoxy (CFE) laminated composites were investigated experimentally. A novel high pressure accelerated aging facility was designed and fabricated for the express purpose of performing accelerated life testing. This facility utilized an elastomeric diaphragm capable of transferring hydraulic oil pressure to a saline water filled volume in order to create a simulation of a deep ocean environment, to which specimens were exposed at elevated temperatures in order to accelerate the rate of water ingression from real world time scales of years to laboratory exposure times of mere days. Utilizing this facility and the Arrhenius relationship for diffusion of water into a polymer matrix composite, the factor of acceleration was determined to be 0.64 years of actual service equivalent to a day of laboratory time at $70^{\circ} \mathrm{C}$. CFE specimens were aged for time periods representing 0 (unweathered), 8.9, and 15.3 years of service. Quasi-static testing revealed no significant degradation of in-plane tensile or shear properties yet $13.8 \%$ and $20.1 \%$ reductions in flexural modulus for the two weathering cases, respectively. Air-blast response was evaluated using a shock-tube apparatus coupled with high frequency response pressure measurement of the shock wave and digital high speed stereo photography. Utilizing the 3D digital image correlation technique and an impulse based normalization procedure, the normalized out-of-plane deflection of the beam did not significantly change with weathering.
\end{abstract}




\section{ACKNOWLEDGMENTS}

The author would like to kindly acknowledge his major professor, Dr. Arun Shukla, for all of his guidance and support from as far back as his undergraduate career as well as all of the teachers and professors from whom he has gleaned so much knowledge over the years. The author is grateful for the opportunity he has been given to participate in this work and grow both as an engineer and as a person. He would also like to acknowledge the eternal support of his family throughout this entire journey and all of the changes that accompanied it. Lastly, he would like to extend his love and gratitude to all of the members of the DPML family. From them he learned much more than how to be a better engineer. 


\section{DEDICATION}

For CGa; you know who you are. 


\section{PREFACE}

This thesis has been formatted in Manuscript Format. Both Manuscripts 1 and 2 will be submitted to scholarly journals for publication: Manuscript 1 to the American Society of Mechanical Engineers Journal of Pressure Vessel Technology and Manuscript 2 to Composites Part B: Engineering. The work contained herein represents a crucial step in the ongoing efforts to understand the behavior of composite materials in one of the most extreme environments on Earth. 


\section{TABLE OF CONTENTS}

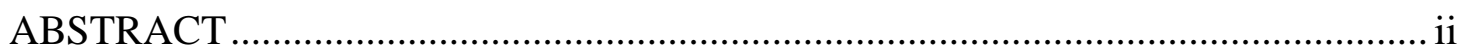

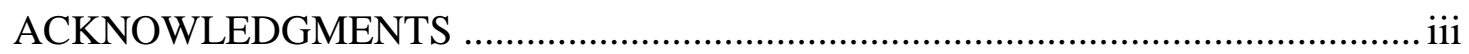

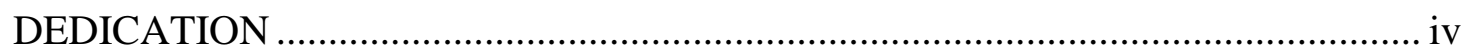

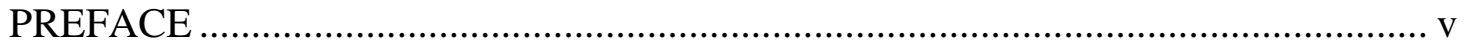

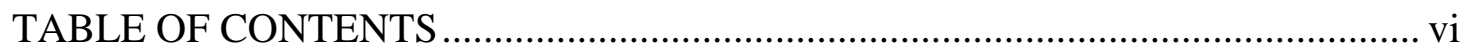

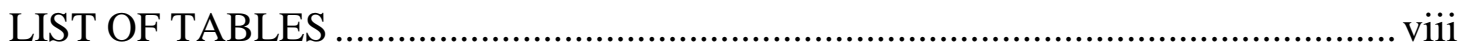

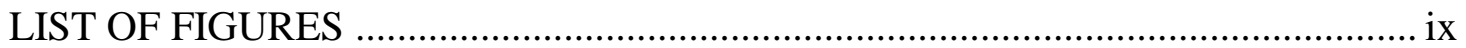

MANUSCRIPT - 1: New Method for Hydrostatic Pressurization of Corrosive Liquids with Applications in Accelerated Life Testing .................................................. 1

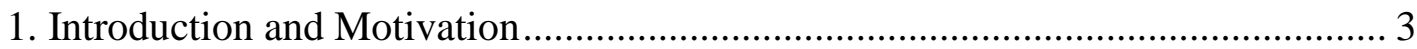

2. Overview of the Pressure Facility .................................................................. 5

3. Basic Components of the Pressure Vessel .......................................................... 6

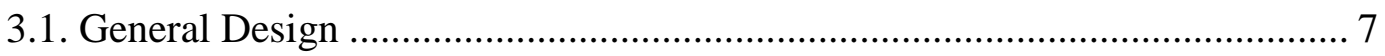

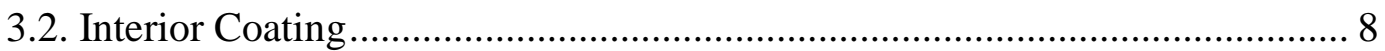

3.3. Plumbing and Pressurizing Equipment........................................................ 9

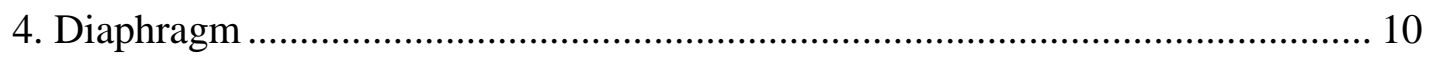

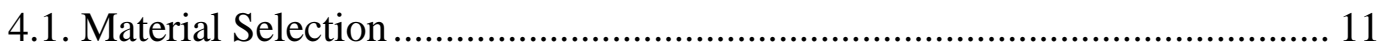

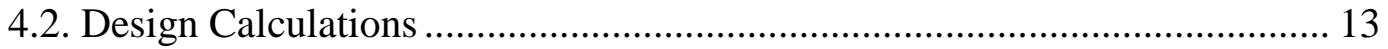

5. Example Usage of the System for ALT ………………................................... 16

6. Discussion and Design Considerations .............................................................. 19

6.1. Thermal Effects................................................................................... 20

6.2. Diaphragm Degradation and Repeatability ................................................. 21

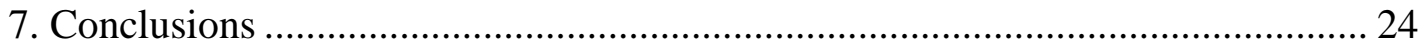


MANUSCRIPT - 2: Blast Response of Carbon-Fiber/Epoxy Laminates Subjected to Long-term Seawater Exposure at Sea Floor Depth Pressures................................. 29

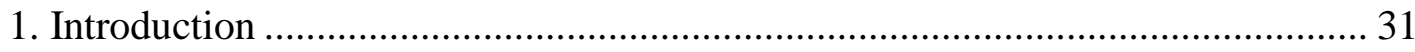

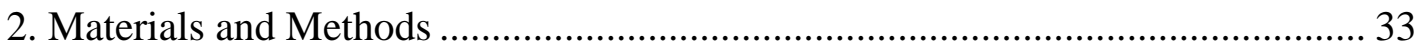

2.1. Material Fabrication and Specimen Geometry …….................................... 33

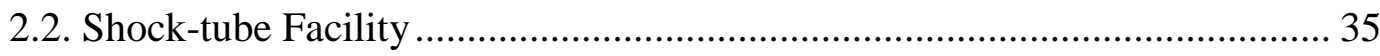

2.3. 3D Digital Image Correlation .................................................................. 36

2.4. High-Pressure Accelerated Aging Facility ………………………………..... 37

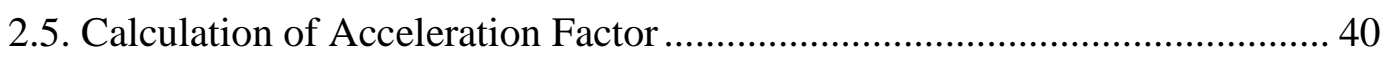

2.6. Quasi-static Testing ............................................................................... 42

3. Experimental Results and Discussion ................................................................ 43

3.1. Results of Diffusion Study ......................................................................... 43

3.2. Results of Quasi-Static Testing.................................................................... 44

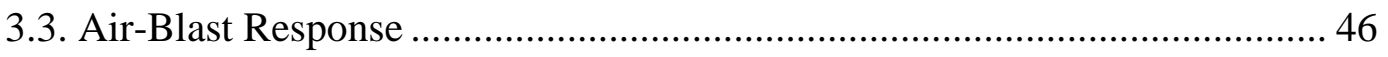

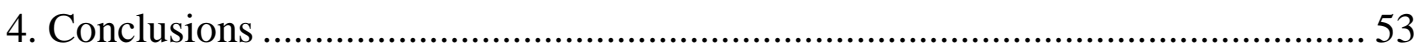

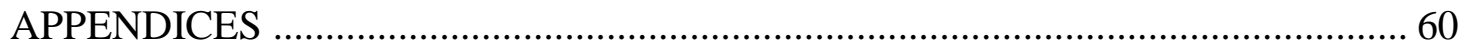

Appendix 1. Introduction, Review of the Problem, and Motivation .......................... 60

Appendix 2. Speculative Discussion and Implications of the Work .......................... 63

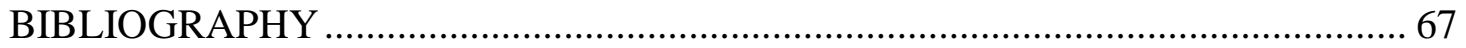




\section{LIST OF TABLES}

Manuscript - 1:

Table 1: Specifications of the Nitrile Diaphragm Material...................................... 13

Table 2: Results of Quasi-Static Tests ............................................................... 19

Manuscript - 2:

Table 1: Specimen Dimensions and Layup Information....................................... 34

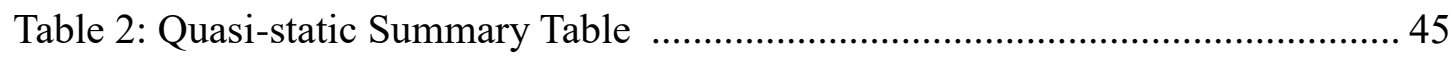

Table 3: Peak Pressures and Non-Dimensional Parameters for the Three Weathering

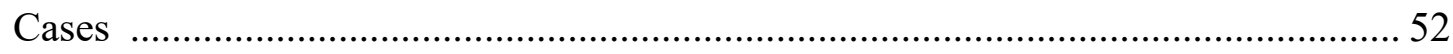




\section{LIST OF FIGURES}

\section{Manuscript - 1:}

Figure 1: Overview of the Accelerated High Pressure Aging Facility....................... 6

Figure 2: Detail of the Plumbing Stem Assembly............................................... 9

Figure 3: Cross-section of the Vessel Showing Plumbing and Internal Workings...... 10

Figure 4: Two diaphragms that have seen service. (a) The water side and (b) oil side of a diaphragm that successfully held test pressure in a room temperature test. There is very little compression set and no visible extrusion. (c) The water side and (d) oil side of a diaphragm that leaked at $35 \mathrm{MPa}$ during a $65^{\circ} \mathrm{C}$ test. The leakage was determined to be the result of catastrophic failure of the underlying O-ring. There is noticeable extrusion and delamination of the face layer at the edges of the clamping zone on the water side. Though there is heavy extrusion into the O-ring glands on the oil side, there is no penetration through the thickness................................................. 12

Figure 5: Engineering Stress-Strain Curves for Quasi-Static In-Plane Tensile Tests on (a) Unweathered, (b) 14 Day, and (c) 24 Day Weathered CFE Specimens and (d) Stress-Strain Curves for Three-Point Bend Tests on the Same Material for the Three

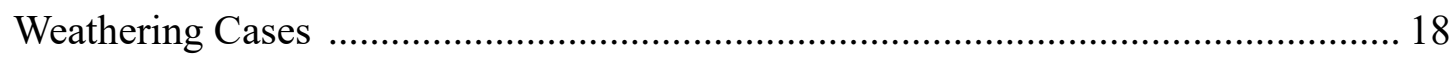

Figure 6: A Post-Mortem Detail of the Diaphragm in Figure 4d ............................ 22

Figure 7: Cross-section of a Diaphragm Showing Damage at the Sealing Locations 23 Manuscript - 2:

Figure 1: Schematic of the Essential Elements of Vacuum Infusion ....................... 34

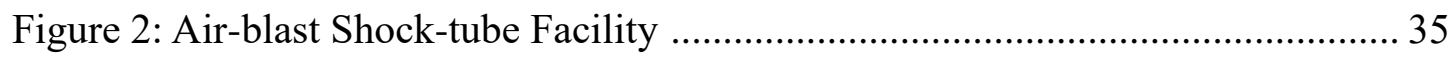


Figure 3: (a) Weathering Facility Overview; (b) Pressure Vessel Used for Diffusion Studies; (c) Pressure Vessel Used for Aging ……………............................................ 38

Figure 4: Example of Polycarbonate Weathering Fixture ............................................ 39

Figure 5: (a) Absorption Curves; (b) Determining Activation Energy from the natural

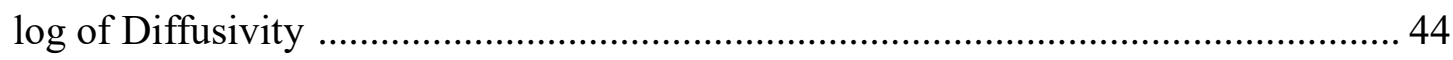

Figure 6: Cross-Fiber Section Schematic of Vacuum Infused Composite with

Unwoven Plies at (a) Ambient Pressure and (b) High Hydrostatic Pressure ............. 46

Figure 7: Typical Loading Curve for the Shock Tube Facility with $0.254 \mathrm{~mm}$

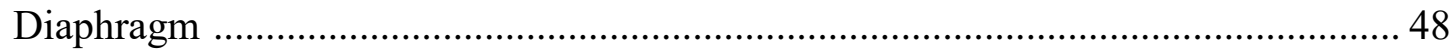

Figure 8: Representative Center Point Out of Plane Displacement Histories for the

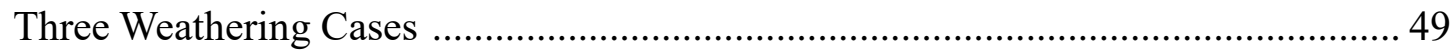

Figure 9: Impulse and Q Curves for the Three Weathering Cases ............................. 51 


\title{
MANUSCRIPT - 1
}

To be submitted for publication in the American Society of Mechanical Engineers

Journal of Pressure Vessel Technology

\section{New Method for Hydrostatic Pressurization of Corrosive Liquids with} Applications in Accelerated Life Testing

\author{
Dillon Fontaine ${ }^{\mathrm{a}}$; Arun Shukla ${ }^{\mathrm{a}}$ \\ ${ }^{a}$ Dynamic Photomechanics Laboratory, Department of Mechanical, Industrial and \\ Systems Engineering, University of Rhode Island, Kingston, RI 02881, USA
}

Corresponding Author: $\quad$ Arun Shukla, Ph.D.

Mechanical, Industrial, and Systems Engineering

University of Rhode Island

94 Upper College Rd.

Kingston, RI, 02881, USA

Email Address: $\underline{\text { shuklaa@uri.edu }}$

Phone: +1-401-874-2283 
Abstract: A system was designed for the performance of high-pressure accelerated life testing (ALT) using saline water solutions and other potentially corrosive media. The system was comprised primarily of a large stainless steel pressure vessel with the capability to perform extended pressure holds of up to $41.3 \mathrm{MPa}$ at temperatures up to $70^{\circ} \mathrm{C}$. Using a nylon fabric reinforced Buna-N rubber diaphragm as a media isolator and an inert ceramic coating on all wetted surfaces of the vessel, $3.5 \%$ saline water solutions were successfully held at test pressures and temperatures for extended periods with no evidence of corrosion or other degradation even after several days of exposure. Pressurization was achieved through a hydraulic pump system, which contained all manner of pressure monitoring equipment and valves and was isolated from the saline water by the diaphragm. The temperature of the entire vessel and contents was maintained by complete immersion in a heated, filtered water bath. The efficacy of using an elastomeric diaphragm to transfer large pressures between two near-incompressible fluids without mixing was shown, provided adequate reinforcement in the form of an interwoven fabric was incorporated to prevent tearing and extrusion from the extreme through-thickness stresses, particularly at clamping locations. Discussion on the effects of temperature, material, thickness, reinforcement, and sealing methods on the effectiveness and repeatability of the system is provided, and a demonstration of an accelerated test on a carbon-fiber composite is also presented. 


\section{Introduction and Motivation:}

Accelerated life testing (ALT) is a common technique used across industries to test the performance of a design throughout, or in some cases to determine, its service life. Common examples of this include accelerating corrosion behavior [1] and determining fatigue and creep parameters [2, 3]. It is a simulated method, the first step of which is to determine factors which are thought to degrade performance. Then, specimens that represent the design are exposed to an environment that accelerates the rate at which these factors act; a common application is to raise the temperature of a humidity chamber or water bath to accelerate the rate of corrosion or moisture ingression. This method has been used recently by various groups to study the effects of marine environments on polymer and composite structures [4-10], which is the primary motivator for this novel facility. As Davies et al. submitted in a review of composite pressure vessels for deep sea applications [11], the demand for greater operating depths and thus higher working pressures is ever increasing, and so this new method was developed motivated primarily by the desire to perform ALT at these deep sea pressures and thus aid design efforts in this regard.

The laboratory environments required to perform this new generation of accelerated testing created a unique challenge in procuring or designing a compatible pressure vessel. The required aging times were as long as 1000 hours, wherein a pressure hold of up to $41.3 \mathrm{MPa}(6000 \mathrm{psi})$ would need be maintained at temperatures of up to $70^{\circ} \mathrm{C}$. This combination of saline media, temperature, and time constituted a severe corrosion risk. Coatings were researched for the interior of the vessel, but these coatings could not reliably be used on moving parts such as needle or pressure relief 
valves, where the extreme sealing pressures required of these devices would surely wear the coatings away after a few uses. Expense was also a concern with this approach, as it was also with procuring exotic metals such as Monel for use in the valves and other pressure equipment. Ultimately this option was deemed too costly and still potentially unreliable, as corrosion may yet attack even these metals after the durations of exposure required by the tests.

One particular design that was considered was inspired by the pressure vessel facility in use at the University of Rhode Island commonly used to study instability and implosion phenomena in thin shells [12-14]. This design uses pressurized nitrogen to fill a small gap of air at the top of the pressure vessel. The pressure is controlled from a remote location by modulating the nitrogen pressure, which by equilibrium, induces the same pressure in the underlying fluid region. A benefit of this design is that the pressure generating, monitoring, and relief equipment as well as any valves do not make contact with the fluid, yet by equilibrium, all measurements of pressure made on the gas are guaranteed to coincide with the actual pressure of the fluid. However, this particular approach was ultimately deemed unsafe for use in the ALT facility, as at the pressures required of a test and for the volume of the vessel, the energies contained in the gas pocket rivaled that of 10 grams of TNT. Additionally, vapors of the process media may yet migrate through whatever gas line exists and still corrode equipment. This combination of explosive potential energy combined with the risk of a seized valve or pressure relief ruled out inert gas as a pressurizing method. Nevertheless, the simplicity of the approach and the concept of isolating the process media from valves and monitoring equipment were desirable qualities that the present 
design leveraged. What follows is a complete description and discussion of that design.

2. Overview of the Pressure Facility

An overview of the accelerated high-pressure aging facility is given in Figure 1. The primary component and focus of this work is a large stainless steel pressure vessel, Figure 1 (a), the inner workings of which will be further elaborated on in subsequent sections. This vessel is attended by a gantry crane which serves to aid transport and also to hoist the vessel into and out of a temperature controlled, filtered water bath (c), used to regulate the temperature of the primary vessel and its contents. A hand-operated hydraulic pump (d) pressurizes the vessel through a hose and high pressure piping stem which contains safety and monitoring equipment. In typical operation, the process media is kept in nearby storage containers (e) and dispensed through a hose. Also present is a small pressure vessel (b) which is used for small specimens and short duration exposures, as it does not have the same corrosion and chemical tolerance of the large vessel. Together, these form a self-contained system for the performance of water ingression type ALT; the smaller vessel is used to study the temperature dependence of water ingression rates through short-term diffusion studies, while the large vessel is for extended aging requiring constant high pressures and elevated temperatures for durations on the order of weeks. 


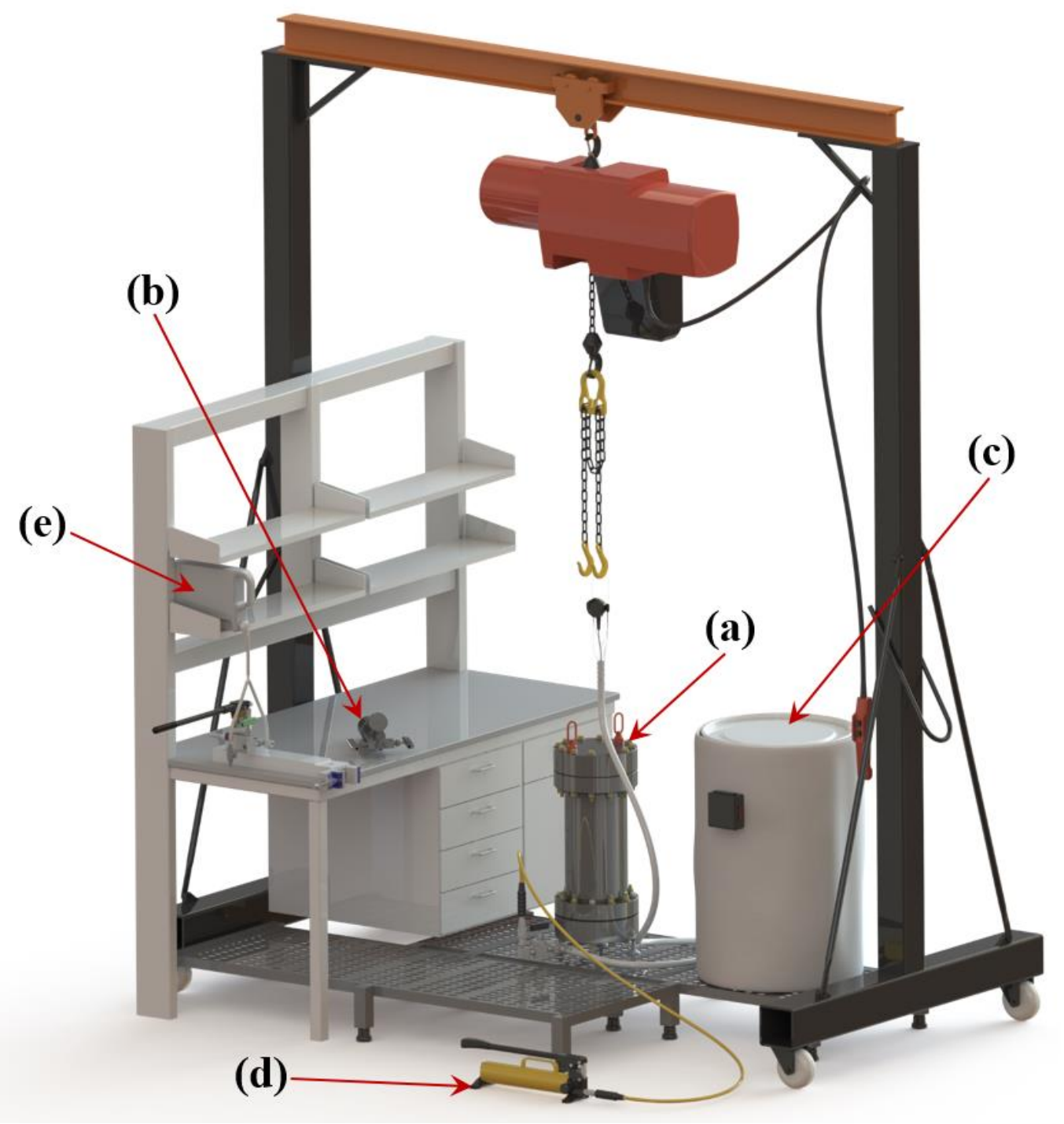

Figure 1: Overview of the Accelerated High Pressure Aging Facility

\section{Basic Components of the Pressure Vessel}

The primary vessel is in most ways of a conventional design except for the diaphragm and manner of pressurizing. These details, while not the focus of this work, are still necessary for the proper understanding of its function and serve to offer some insight as to the reliability and reusability of the system, so they will be presented briefly in this section. 


\subsection{General Design}

The vessel follows a fairly conventional flanged-end design, comprised of five structural components: an upper and lower flat profile end-cap, two flanges, and a central body section. All of these parts were fabricated from AISI 304L stainless steel, which was chosen for its good balance of strength, corrosion resistance, machinability, and creep behavior. The body section fully defines the usable volume of the pressure vessel and is a single section of centrifugally cast, seamless tube $53.3 \mathrm{~cm}$ in length with an internal diameter of $15.2 \mathrm{~cm}$ and wall thickness of $3.81 \mathrm{~cm}$. The ends of the body are externally threaded to accept the flanges, and the top end face is trepanned for an $\mathrm{O}$ ring gland accepting a No. 441 O-ring used as a face seal between the body and top end-cap. The bottom end-cap is $30.5 \mathrm{~cm}$ in diameter and $8.26 \mathrm{~cm}$ thick, with a concentric through hole tapped for a 3/8-18 NPT thread on both ends by which the plumbing from the pump connects. Offset a small distance from this center hole is a plugged 1/8-27 NPT through hole acting as an air bleeder. On the top surface in the region in contact with the body section are two concentric O-ring grooves sized for No. 439 and 444 nitrile rings. Only the innermost ring is sealing; the second trepan serves to concentrate clamping pressure on the diaphragm by reducing the area in contact, thereby affecting a better seal.

The top end-cap is of identical base dimensions as the bottom except without the through holes. On the top surface are two shallow tapped blind holes into which threaded hoisting rings are fastened, which allow the vessel to be lifted by the gantry crane seen in Figure 1. The flanges are threaded onto the body, and the caps are 
fastened to the flanges by 12 1/2-20 UNF Grade 9 bolts and nuts at both top and bottom. However, in the bottom, every third bolt is replaced by a longer one which terminates in a swiveling foot, which gives the vessel about $75 \mathrm{~mm}$ of ground clearance and allows the plumbing to attach directly to the bottom of the lower endcap.

\subsection{Interior Coating}

All surfaces expected to be in contact with the process media were coated with Cerakote Elite Series E190 (Cerakote Inc., White City, OR). This includes the entire inside cylindrical surface of the body section, the top and bottom end faces of the body including the O-ring gland, and the bottom surface of the top end-cap which lies in contact with the face seal and encloses the pressurized volume. Cerakote Elite Series is a resin based ceramic thin film coating which was chosen primarily for its excellent hardness and corrosion resistance, with survivability of the coating exceeding 4000 hours in an ASTM B117 salt spray test [15]. The coating was also noted for its flexibility and adhesion, important concerns when taking thermal expansion and cycling into account, combined with large compressive stresses. Application of the coating was conducted according to manufacturer's instructions by DiFruscia Industries Inc. (Johnston, RI), a Cerakote licensed applicator. This coating allows the interior of the vessel to handle many different corrosive liquids directly, including the salt water used in many ALT's. 


\subsection{Plumbing and Pressurizing Equipment}

All manner of plumbing, pressurizing, and pressure monitoring equipment is attached to the vessel at the 3/8-18 NPT tap at the bottom of the lower end-cap, as shown in Figure 2. The assembly consists of an elbow threaded into the bottom endcap which then routes a pipe nipple between the legs of the vessel. Following this is a cross into which a pressure transducer is threaded on one side, and a safety head with a rupture disc is threaded on the other. This rupture disc is set to burst at a pressure slightly higher than the vessel's maximum allowable working pressure of 41.3MPa, and well below the design failure pressure. Following the cross is a needle valve which serves to fully isolate the vessel, terminating in a hydraulic coupler that allows connection to the pump.

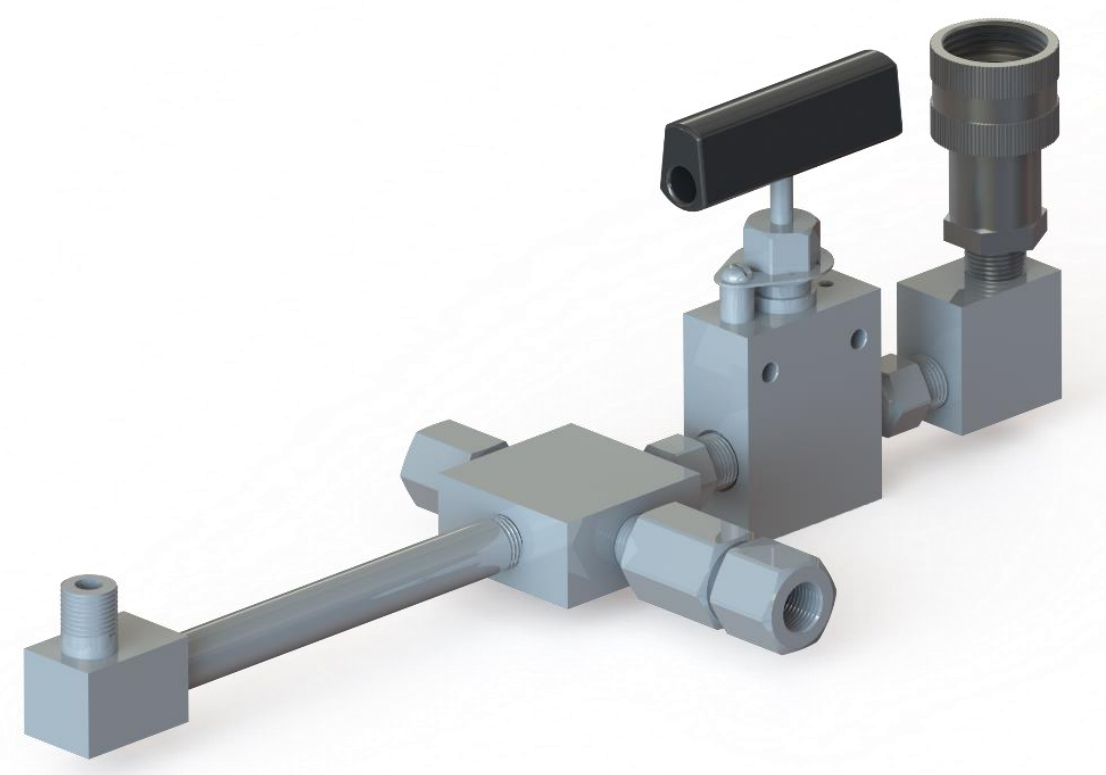

Figure 2: Detail of the Plumbing Stem Assembly 
The pump used was an Enerpac P39 (Enerpac, Inc., Menomonee Falls, WI) hand operated hydraulic pump, although the standard connections on the vessel allow for any hydraulic pump to be used. The vessel does not have a separate valve for pressure release, although the design is flexible enough to include one, which motivated the use of a single-acting pump with integral release valve. An elastomeric hydraulic hose connects the pump to the plumbing assembly.

\section{Diaphragm}

The corrosive nature of the proposed process media at the design specified temperatures necessitated a novel approach for a method of pressurization for the vessel. As discussed, several possible options were considered and ruled out for their added expense and/or safety concerns.

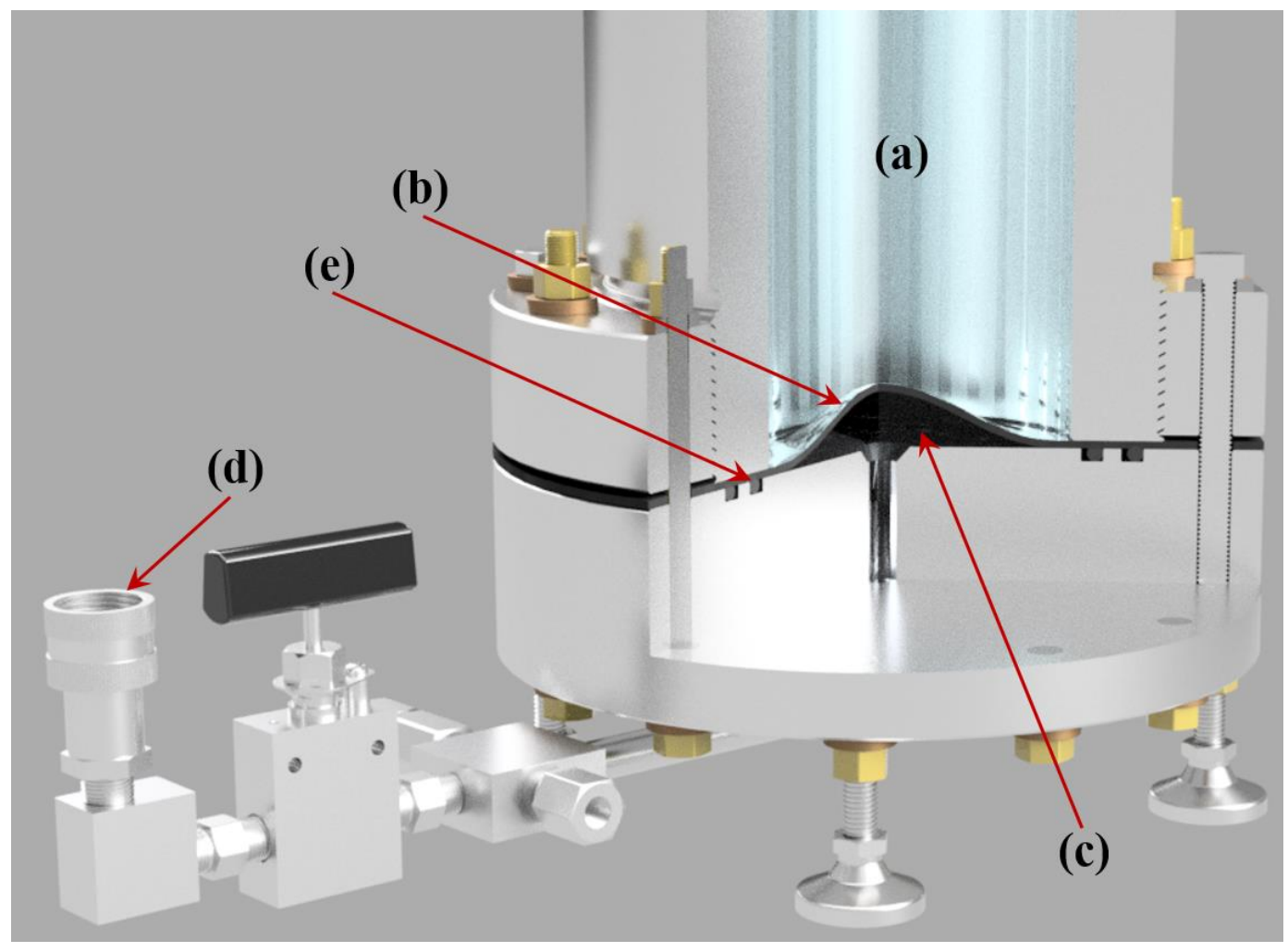

Figure 3: Cross-section of the Vessel Showing Plumbing and Internal Workings 
Ultimately, a novel diaphragm approach was chosen as a media isolator between the process media and any viable pressurizing media, in practice a stable hydraulic oil. The principles of its operation are shown in the cross-section rendering of Figure 3. The water domain contained in the pressure vessel's usable volume is seen at (a). Hydraulic oil is pumped through the plumbing stem at the connector (d), as discussed in Section 3.3. The oil flows through the central hole in the lower end-cap and pushes against the diaphragm (b), occupying a volume (c). This decreases the volume of the water domain, inducing a pressure in it nearly equal to that in (c), save for the diaphragm's resistance to deflection. The diaphragm is sealed on the oil side by Orings at (e), as well as by compression in the band of material between the glands. Because some pressure is required to deform the diaphragm into its bell-like shape, the oil pressure is naturally slightly higher, and so a gasket style seal is all that is required between the diaphragm and the lower end face of the body section. Details on the material and construction of the diaphragm as well as design calculations for the diaphragm are given in the following sections.

\subsection{Material Selection}

Two used diaphragms are shown in Figure 4. Constructed of a nylon fabric reinforced Buna-N (nitrile) sheet with part number C2500-0125-121 (BRP Manufacturing, Inc., Lima, Ohio), the material has characteristics given in Table 1. 


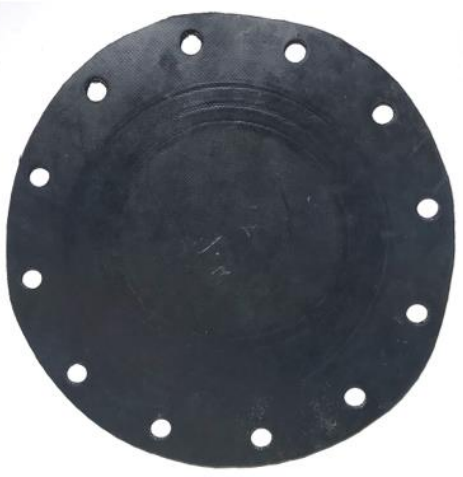

(a)

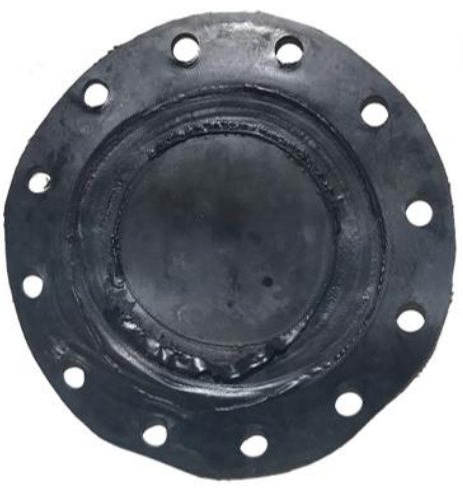

(c)

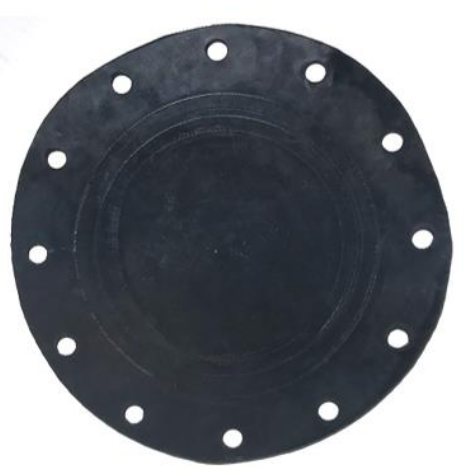

(b)

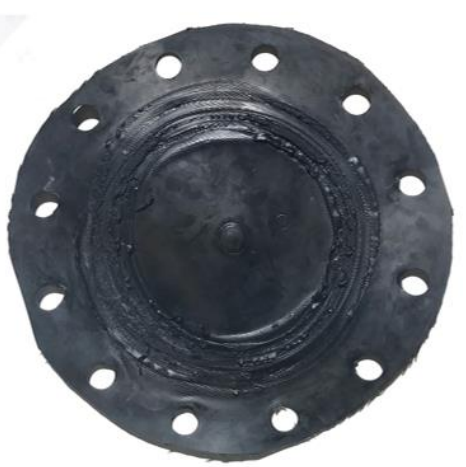

(d)

Figure 4: Two diaphragms that have seen service. (a) The water side and (b) oil side of a diaphragm that successfully held test pressure in a room temperature test. There is very little compression set and no visible extrusion. (c) The water side and (d) oil side of a diaphragm that leaked at $35 \mathrm{MPa}$ during a $65^{\circ} \mathrm{C}$ test. The leakage was determined to be the result of catastrophic failure of the underlying $O$-ring. There is noticeable extrusion and delamination of the face layer at the edges of the clamping zone on the water side. Though there is heavy extrusion into the O-ring glands on the oil side, there is no penetration through the thickness.

The rubber itself has an ASTM D2000 [16] standard callout of 2BG515A14B14C12E014E034F19, as reported by the manufacturer [17]. The fabric is a plain woven, high tensile strength nylon manufactured by DuPont (Wilmington, DE). This material was chosen because of its good chemical resistance to all of the process media anticipated to be used with the facility. 
Table 1: Specifications of the Nitrile Diaphragm Material

\begin{tabular}{|c|c|c|c|c|}
\hline $\begin{array}{c}\text { Thickness } \\
(\mathbf{m m})\end{array}$ & $\begin{array}{c}\text { Areal } \\
\text { Density } \\
\left(\mathbf{k g} / \mathbf{m}^{\mathbf{2}}\right)\end{array}$ & $\begin{array}{c}\text { No. of cloth } \\
\text { plies }\end{array}$ & Cloth Type & $\begin{array}{c}\text { Cloth } \\
\mathbf{W e i g h t} \\
\left(\mathbf{g} / \mathbf{m}^{\mathbf{2}}\right)\end{array}$ \\
\hline 2.98 & 3.20 & 2 & $\begin{array}{c}\text { Biaxial } \\
\text { plain woven }\end{array}$ & 373 \\
\hline
\end{tabular}

Nitrile is a common seal material particularly around hydraulic oils, and nylon was chosen because of its tolerance to both salt water and oils in case the face sheet of the rubber was penetrated in any way exposing the cloth. A cloth reinforcement is highly desirable as it was shown to maintain dimensional stability and limit compression set when used in the high pressure seals of the vessel. Whereas unreinforced nitrile of similar hardness was seen to extrude at the sealing locations, much of this was seen to be mitigated by the presence of the cloth. More discussion on the effects of extrusion and compression set will be presented in Sections 6.1 and 6.2.

\subsection{Design Calculations}

In this section, the average strain on the diaphragm will be calculated and the pressure difference between process and pressurizing media domains estimated. It is assumed that the diaphragm behaves effectively isotropically for small strains, which is valid when one considers that the difference in cloth areal density and bulk material areal density. The handbook value for the density of nitrile rubber is approximately $1200 \mathrm{~kg} / \mathrm{m}^{3}$ [18], which, when factoring in the thickness of the diaphragm leads to an areal density of $3.60 \mathrm{~kg} / \mathrm{m}^{2}$. This implies the diaphragm material is nearly $88 \%$ nitrile by volume. Additionally, when considering the cloth is unstressed and not pulled 
taught within the nitrile, nor are individual fibers taught within each thread, a majority of any applied load at small strains will not have overcome the pre-stress required to fully engage the cloth fibers, and so it is a fair assumption that at small strains, the material overall behaves much like unreinforced nitrile, which is an isotropic elastomer with typical M100 modulus of 3.00MPa [18] and a Poisson's ratio of approximately 0.49 , typical for elastomers. Hermida [19] derived equations for a circular diaphragm clamped at its edges and subjected to a pressure difference. The vertical deflection, $w$, (excursion into the process media) is given by the following equation:

$$
w(r)=w_{0}\left[1-\left(\frac{r}{a}\right)^{2}\right]^{2}
$$

where $w_{0}$ is the maximum excursion at the center of the diaphragm, $r$ is the radial coordinate from the center, and $a$ is the radius of the clamped boundary. $w_{0}$ is further given by the following equation:

$$
w_{0}=\alpha a * \sqrt[3]{\frac{q a}{E h}}
$$

where $q$ is the differential pressure, $E$ is the modulus of elasticity, $h$ is the thickness of the diaphragm, and $\alpha$ is a dimensionless parameter defined in terms of Poisson's ratio, $v$, as follows:

$$
\alpha=\sqrt[3]{\frac{6615\left(v^{2}-1\right)}{2\left(2791 v^{2}-4250 v-7505\right)}}
$$

For a Poisson's ratio of 0.49 , this parameter evaluates to 0.656 .

Additionally, the design pressure for the vessel is $41.3 \mathrm{MPa}$, with a maximum operating temperature of $70^{\circ} \mathrm{C}$. Fine and Millero give the compressibility of water at 
various temperature and pressure combinations in the neighborhood of these design values [20]. Using these values and the definition of bulk modulus, $K$, as the reciprocal of compressibility, a conservative average bulk modulus for the water domain across the range of design pressures and temperatures is $2.55 \mathrm{GPa}$. The volume change, $\Delta V$, of a fluid under pressure is a well-known equation:

$$
\Delta V=\frac{V_{0} \Delta P}{K}
$$

where $V_{0}$ is the original volume and $\Delta P$ is the change in pressure. Because the vessel is initially at ambient pressure and the design value is relative to this pressure, $\Delta P$ is automatically the design value. Using the dimensions given in Section 3.1 for the usable volume of the vessel, this reduction in volume was calculated to be $135 \mathrm{~mL}$. Because the diaphragm is circular and thin, the volume the water compresses by to achieve a certain pressure is equal to the volume contained by the deformed diaphragm shape relative to its initial profile. This amounts to simply the volume of a revolution of the deformed profile about the $r=0$ axis, given by the following:

$$
\Delta V=2 \pi \int_{0}^{a} r|w(r)| d r
$$

By substituting Eq. 1 into Eq. 5 and solving for $w_{0}$ given the value of $\Delta V$ calculated from Eq. 4, the maximum excursion of the diaphragm was found to be $22.2 \mathrm{~mm}$. The average strain along the radius can be obtained by comparing the arc-length of half the deformed shape to the initial value of simply $a$. Doing so results in an increase from $76.2 \mathrm{~mm}$ to $80.0 \mathrm{~mm}$, or a $5 \%$ average radial strain. This value is low enough in comparison to the failure strains of either material to conclude that the diaphragm should not tear from membrane strains and is also of a magnitude where the stiffness 
assumptions hold. Additionally, by substituting the maximum excursion value into Eq. 3 and solving for $q$, which is a good estimator of the pressure drop between the process and pressurizing domains, a value of $10.3 \mathrm{kPa}$ is obtained, which is a negligible difference within the margin of error of most gauges used in the vessel's pressure range. It should be noted that this pressure drop and membrane strains may actually be significantly less due to the Poisson effect. As the diaphragm experiences large compressive stresses through the thickness, these will tend to relieve the in-plane tension of the membrane stresses, possibly even overcompensating and leading to wrinkling of the diaphragm.

\section{Example Usage of the System for ALT}

This system was designed primarily to conduct water ingression type accelerated life tests. Many polymers and polymer matrix composites (PMC's) have been known to respond negatively to long-term exposure to a marine environment, with significant degradation in mechanical properties being the norm. Diffusion of water into polymers under large hydrostatic pressures is a relatively well studied phenomenon, yet the effects on mechanical properties has not been well investigated. Additionally, due to the complications of pressurizing heated saline water that this system addresses, previous work has almost exclusively used pure, deionized water with the assumption that the added salt does not have an appreciable effect. To bridge this gap in the body of knowledge, a study was performed which investigated both the quasi-static and dynamic performance of carbon fiber / epoxy (CFE) PMC's after being subjected to sea-floor depth pressures for simulated time scales on the order of 
years. A summary of some of the results from this study is provided below, with the unexpected results highlighting the necessity to study composite materials in such an environment.

First, a diffusion study was performed which characterized the temperature dependence of the diffusivity of water into the composite. This was accomplished utilizing the small pressure vessel shown in Figure $1 \mathrm{~b}$ and drawing absorption curves at high pressure and over a range of temperatures. Once the temperature dependence was quantified, a quantity known as the acceleration factor, $A F$, was calculated which related in-laboratory exposure time at elevated temperatures with real world service time at lower temperatures. For the specific PMCs used in this study, the acceleration factor was determined to be $0.64 \mathrm{yr} / \mathrm{day}$ when aging at a temperature of $70^{\circ} \mathrm{C}$ and pressure of 41.3MPa. Three weathering cases were chosen, an unweathered baseline, 14 days, and 24 days, equivalent to $0,8.9$ and 15.3 years of actual service, respectively. Aging was performed using the Accelerated High Pressure Aging Facility as documented in this article.

Specimens were cut using a diamond saw to dimensions as close as feasible to those set forth in ASTM D3039 [21] for tension coupons and ASTM D7264-15 [22] for three-point bend coupons. Tensile tests were carried out in an Instron 5585 universal test frame equipped with a $250 \mathrm{kN}$ load cell and taken to failure, while threepoint bend tests were carried to $15 \mathrm{~mm}$ center deflection of a $20 \mathrm{~cm}$ span. The engineering stress-strain curves are shown in Figure 5. The tensile behavior of the composite was unchanged by aging, with a linear trend persisting until ultimate failure, as expected. 

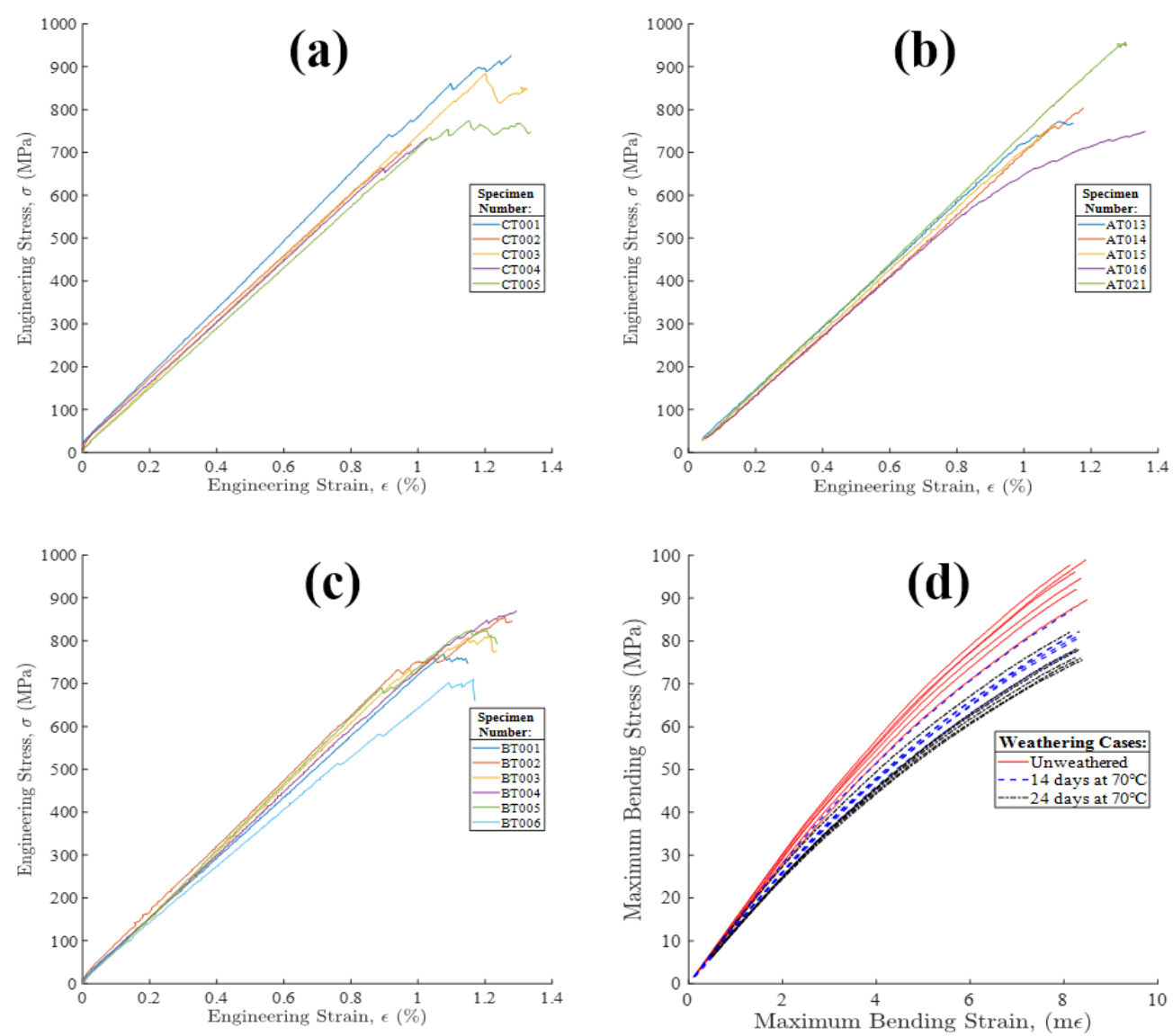

Figure 5: Engineering Stress-Strain Curves for Quasi-Static In-Plane Tensile Tests on (a) Unweathered, (b) 14 Day, and (c) 24 Day Weathered CFE Specimens and (d) Stress-Strain Curves for Three-Point Bend Tests on the Same Material for the Three Weathering Cases

However, flexural behavior is highly affected by moisture ingression, decreasing significantly as aging time increases. Further analysis of the stress-strain data allowed the calculation of the average tensile moduli, flexural moduli, and tensile stresses and strains at failure for the three weathering cases, given in Table 2. Most notably, the tensile modulus is unchanged by weathering, the observed differences being within a 95\% margin of error for each test, while flexural modulus decreases significantly, by $13.2 \%$ and $20.8 \%$ after 14 and 24 days of exposure, respectively. 
Table 2: Results of Quasi-Static Tests

\begin{tabular}{|c|c|c|c|}
\hline Parameter & Unweathered & 14 Day & 24 Day \\
\hline Tensile Modulus (GPa) & 71.87 & 73.00 & 72.56 \\
\hline Flexural Modulus (GPa) & 13.9 & 12.1 & 11.0 \\
\hline $\begin{array}{c}\text { Maximum Tensile } \\
\text { Stress (MPa) }\end{array}$ & 813 & 809 & 807 \\
\hline $\begin{array}{c}\text { Strain at Max Tensile } \\
\text { Stress (\%) }\end{array}$ & 1.03 & 1.13 & 1.20 \\
\hline
\end{tabular}

Due to the variability in general of failure of polymer-matrix composites, the differences in tensile failure stresses and strains are not statistically significant, and thus the common trend of increased degradation with aging was not present in tension during this high pressure study, though flexural properties degraded at similar rates to what would be expected. Although work is ongoing to further study this phenomenon, it is speculated that the large hydrostatic pressures, while aiding diffusion on a macroscopic level, closes voids at the matrix-fiber interface and forces the ingressed water to concentrate between plies, thus leaving the in-plane properties relatively unchanged. This was a completely unexpected result and shows the validity of using this system for performing high pressure ALT's.

\section{Discussion and Design Considerations}

The diaphragm and O-ring seals, being composed of elastomers, are naturally sensitive to changing temperatures and thermocycling. Also, because the diaphragm is effectively a composite of nitrile and nylon, there are additional potential complications of delamination due to through-thickness stress and dissimilar rates of 
thermal expansion. In this section, discussion of these factors will be presented based on various observations made during the prototyping and testing stage.

\subsection{Thermal Effects}

The effects of temperature on the diaphragm can plainly be seen by comparing the two sample diaphragms shown in Figure 4, both of which saw similar pressures but at different temperatures. Raising the temperature softened the diaphragm material and increased the amount of extrusion into the oil-side O-ring glands. During a $65^{\circ} \mathrm{C}$ test where leakage occurred at approximately $35 \mathrm{MPa}$, inspection found catastrophic failure of the inner O-ring to be the immediate cause. Heavy extrusion and partial delamination of the outermost layer of rubber from the cloth can be seen at this location in Figure 4d, suggesting that the problem was multifaceted. While the delamination was likely the result of the violent tearing nature of the failure, the extrusion of both diaphragm and O-ring material, which were both similar grades of nitrile, suggest thermal softening of both parts played a role. O-ring extrusion occurs in a face seal when the gap size between the faces reaches a critical size for the O-ring and pressure. A soft O-ring at higher pressures is much less tolerant of a gap than a hard O-ring at lower pressures. It is thought that because the flange was tightened at ambient temperature, as the temperature increased and both diaphragm and O-ring softened, the pressure was enough to open a gap between the now compliant diaphragm and lower end-cap, a gap the O-ring could not tolerate.

To counteract this problem, two modifications were implemented with success. Firstly, the nitrile O-rings were replaced with FKM of a higher durometer rating. FKM 
flouroelastomer rings are known to retain their stiffness better at higher temperatures, and the higher hardness was chosen to increase gap tolerance and lower the risk of extrusion. Additionally, the assembly procedure for the bottom seal was modified to incorporate pre-heating. The diaphragm and O-rings were installed as before at ambient temperatures and the bolts tightened, but then the entire vessel was heated at the maximum operating temperature of $70^{\circ} \mathrm{C}$ and allowed to come to thermal equilibrium over the course of several hours. The vessel was empty during this time and any pressure caused by heating was allowed to release. Then the bolts were tightened to their torque specifications once again to take up the increased compliance of the diaphragm due to heating. A slight increase in the compliance was in fact noticed by the apparent loosening of the bolts before their retightening. Together, these two modifications proved successful in maintaining integrity of the seal, as the vessel was cycled several times and allowed to hold pressure for several days without issue before it was once again disassembled to check for any degradation of the diaphragm.

\subsection{Diaphragm Degradation and Repeatability}

A detail of the diaphragm shown in Figure $4 d$ is shown in Figure 6. The modes of degradation of this example serve as good examples of the types of deterioration that can occur in this system if proper countermeasures are not put into effect. In Figure 6a, the primary extrusion lobe can be seen, where the diaphragm material begins to be forced into the inner O-ring gland. Moving outwards radially, some delamination of the outer rubber face from the lower cloth ply is seen. The severity of 
this delamination is most likely the result of the sudden failure of the O-ring and the large release of pressure that followed, and not from normal service. It should be noted that even with this delamination, only the outer face is affected; the core layer of rubber which is sandwiched between two plies of cloth is undamaged and so the process and pressurizing media remained isolated even after failure. More delamination is seen in Figure 6b, this time occurring over the secondary O-ring gland. Once again, only the outermost layer of rubber is affected, and the middle and top layers of rubber are not penetrated.

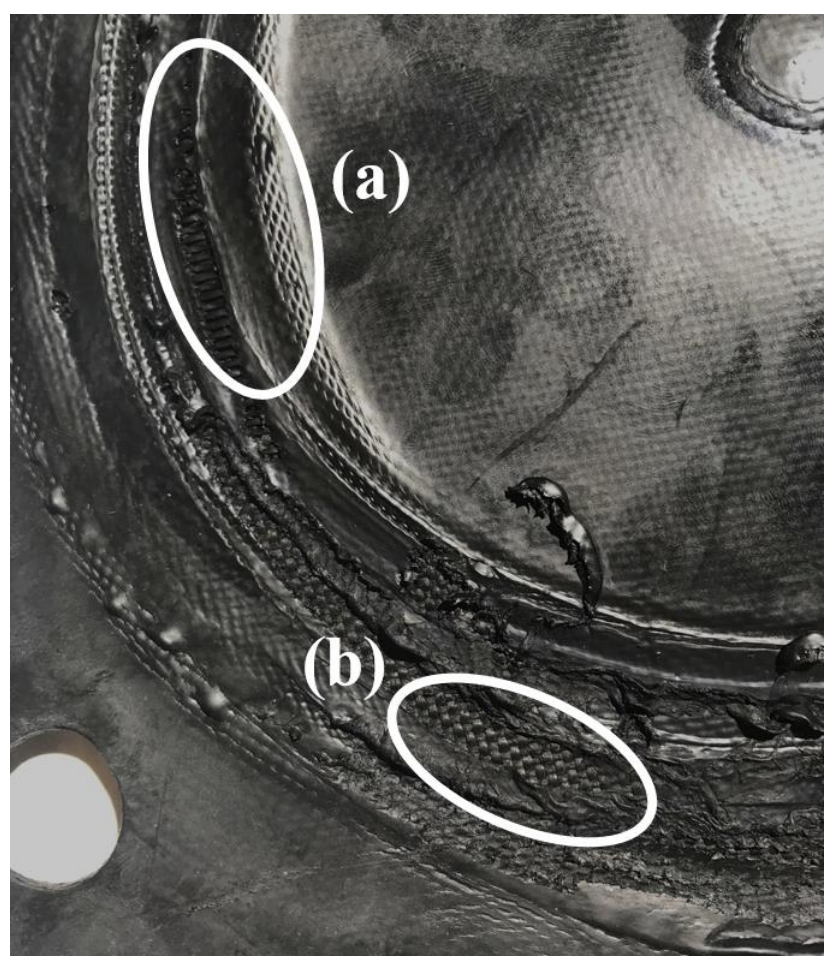

Figure 6: A Post-Mortem Detail of the Diaphragm in Figure 4d

The cause of this is thought to be the discontinuity in through-thickness compression at the edge of the O-ring gland combined with thermal softening of the nitrile. The compression on either side of the discontinuity combined with the Poisson effect most 
likely formed the softened rubber into a lobe or bubble, which was torn by the sudden friction of the extruding O-ring and the subsequent release of pressure.

Additionally, small amounts of delamination were observed on the water side, due to the clamping pressure of the body section against the lower end-cap. This can be seen in Figure 7, a cross section of a diaphragm that leaked slightly after several hours of test pressure hold but did not fail catastrophically. A primary delamination lobe is seen at (a), where in-plane compression due to bending of the diaphragm into the water section combined with the through thickness pressure to cause some separation of the rubber face. Once again, the reinforcing nature of the cloth restricted the inner rubber layer from doing the same, and thus there was no through-thickness penetration. A similar phenomenon was observed on the outer edge of the seal at (b), although it is not as pronounced as at (a) due to the lack of pressure on the outlying portions of the diaphragm. The cloth is exposed in a similar manner as can be seen at Figure 6b.

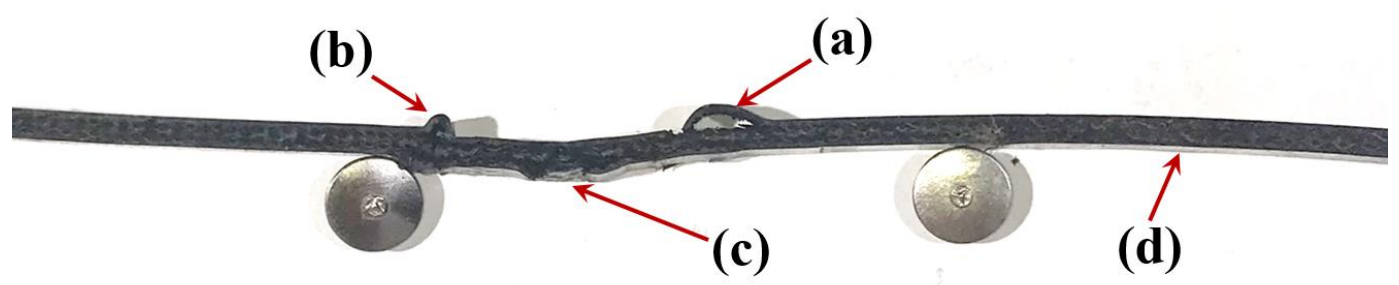

Figure 7: Cross-section of a Diaphragm Showing Damage at the Sealing Locations

Additionally, extrusion at the O-ring glands can be seen at Figure 7c, but there does not appear to be delamination of the rubber at this location. On the interior portions of the diaphragm where the through-thickness stress is constant without discontinuities at 
the boundaries, seen at (d), the material is unaffected; the strength of the nylon cloth is enough to prevent the nitrile from extruding without delaminating.

In summary, most if not all damage to the diaphragm occurs at stress discontinuities at the boundaries of the water side seal and at the edges of the O-ring glands. The severity of the damage is heavily dependent on temperature and the softening of the nitrile at elevated temperatures. It is thought that hardening the nitrile at these locations, perhaps by a chemical treatment or the bonding of a hard polymer to the face layers, would significantly reduce the probability of this damage progressing and increase the reliability of the system as a whole.

\section{Conclusions}

A new system was developed for the pressurization of corrosive media at high pressures for extended periods of time and at elevated temperatures. The interior of this system was coated in an inert ceramic / epoxy coating which provided adequate corrosion protection for all manner of static sealing. Using a fabric reinforced nitrile diaphragm combined with flouroelastomer supplementary seals, the corrosive process media, in testing a saline water solution, was isolated from all manner of pressure generating, monitoring, and safety equipment, while reliably transferring pressure from the hydraulic actuating media to the saline water. The design was shown to be simple and modular while still affording the same level of safety as traditional pressure vessels. The system was shown to have applications in accelerated life testing, particularly for deep ocean environments, where the effects of long-term 
storage on the sea floor on the flexural and in-plane tensile properties of carbon-fiber / epoxy laminates were investigated experimentally.

Acknowledgements

The authors would like to kindly thank Dr. Maria Medeiros from the Office of Naval Research for financial support under Grant No. N00014-18-1-2641, as well as colleagues at the Dynamic Photomechanics Laboratory, for their prudent moral support and experimental advice. Thanks also to Joe Gomez, and Dave Ferreira for helping the author's construct the prototype of this design. Lastly, the authors would like to extend appreciation to Dr. Carlos Javier and Dr. James LeBlanc from the Naval Undersea Warfare Center-Newport for their advice and support, and a very heartfelt thanks to Anthony Marshall for assisting with every facet of this research, from design, fabrication, and testing, to experimentation and analysis.

\section{References}

1. Al-Mazrouee, A., and Singh Raman, R. K. (September 21, 2006). "High Temperature Oxidation of Cr-Mo Steels in the Context of Accelerated Rupture Testing for Creep Life Prediction." ASME. J. Pressure Vessel Technol. August 2007; 129(3): 454-459. https://doi.org/10.1115/1.2748826

2. Guo, J. Q., Li, F., Zheng, X. T., Shi, H. C., and Meng, W. Z. (February 5, 2016). "An Accelerated Method for Creep Prediction From Short Term Stress Relaxation Tests." ASME. J. Pressure Vessel Technol. June 2016; 138(3): 031401. https://doi.org/10.1115/1.4032109 
3. Zuo, M., Chiovelli, S., and Nonaka, Y. (July 6, 2000). "Fitting Creep-Rupture Life Distribution Using Accelerated Life Testing Data ." ASME. J. Pressure Vessel Technol. November 2000; 122(4): 482-487. https://doi.org/10.1115/1.1310164

4. Kishore, Barpanda, P., \& Kulkarni, S. M. (2005). Compression strength of saline water-exposed epoxy system containing fly ash particles. Journal of Reinforced Plastics and Composites, 24(15), 1567-1576. https://doi.org/10.1177/0731684405050390

5. Papanicolaou, G. C., Kosmidou, T. V., Vatalis, A. S., \& Delides, C. G. (2006). Water absorption mechanism and some anomalous effects on the mechanical and viscoelastic behavior of an epoxy system. Journal of Applied Polymer Science, 99(4), 1328-1339. https://doi.org/10.1002/app.22095

6. Shillings, C., Javier, C., LeBlanc, J., Tilton, C., Corvese, L., \& Shukla, A. (2017). Experimental and computational investigation of the blast response of Carbon-Epoxy weathered composite materials. Composites Part B:

Engineering, 129, 107-116. https://doi.org/10.1016/j.compositesb.2017.07.023

7. Matos, H., Javier, C., LeBlanc, J., \& Shukla, A. (2018). Underwater nearfield blast performance of hydrothermally degraded carbon-epoxy composite structures. Multiscale and Multidisciplinary Modeling, Experiments and Design, 1(1), 33-47. https://doi.org/10.1007/s41939-017-0004-6

8. Tucker, W. C., \& Brown, R. (1989). Moisture Absorption of Graphite / Polymer Composites Under 2000 Feet of Seawater, Journal of Composite Materials, 23(8), 787-797 https://doi.org/10.1177\%2F002199838902300802 
9. Rice, M., \& Ramotowski, T. (2011). Activation energy calculation for the diffusion of water into PR-1590 and pellethane 2103-80AW polyurethanes. NUWC-NPT Technical Memo, 11-062.

10. Le Gac, P.-Y., Davies, P., \& Choqueuse, D. (2015). Evaluation of Long Term Behaviour of Polymers for Offshore Oil and Gas Applications. Oil \& Gas Science and Technology - Revue d'IFP Energies Nouvelles, 70(2), 279-289. https://doi.org/10.2516/

11. Davies, P., Choqueuse, D., Bigourdan, B., and Chauchot, P. (July 18, 2016). "Composite Cylinders for Deep Sea Applications: An Overview." ASME. J. Pressure Vessel Technol. December 2016; 138(6): 060904. https://doi.org/10.1115/1.4033942

12. Pinto, M., Gupta, S., and Shukla, A. (October 1, 2015). "Hydrostatic Implosion of GFRP Composite Tubes Studied by Digital Image Correlation." ASME. J. Pressure Vessel Technol. October 2015; 137(5): 051302.

https://doi.org/10.1115/1.4029657

13. Pinto, M., Matos, H., Gupta, S., and Shukla, A. (July 18, 2016). "Experimental Investigation on Underwater Buckling of Thin-Walled Composite and Metallic Structures." ASME. J. Pressure Vessel Technol. December 2016; 138(6): 060905. https://doi.org/10.1115/1.4032703

14. Gupta, S., Parameswaran, V., Sutton, A., and Shukla, A. Study of dynamic underwater implosion mechanics using digital image correlation. 470 Proc. R. Soc. A. https://doi.org/10.1098/rspa.2014.0576 
15. Cerakote, Inc. 2019. "Cerakote Elite Series Technical Data Sheet," Data Sheet. Last Revised November 12, 2019.

16. ASTM D2000-18, Standard Classification System for Rubber Products in Automotive Applications, ASTM International, West Conshohocken, PA, 2018, www.astm.org

17. BRP Manufacturing, Inc., 2020, "Diaphragm Nitrile Specification SheetC500," Data Sheet, accessed February 4, 2020, http://brpmfg.com/wpcontent/uploads/2016/08/Nitrile-Nylon-Iserted-Diaphrgam-Sheet-C500-PBWeb-10-14-.pdf

18. Khairi N., "Rubber as an Engineering Material: Guideline for Users," Hanser Publishers, Munich, 1993.

19. Hermida, A., "Deflection of Circular Membrane Under Differential Pressure," NASA Tech Briefs, Vol. 22, No. 5 (May 1998), page 78

20. Fine, Rana A., Millero, Frank J., "Compressibility of water as a function of temperature and pressure," J. Chem. Phys. 59, 5529 (1973); https://doi.org/10.1063/1.167990359

21. ASTM D3039 / D3039M-17, Standard Test Method for Tensile Properties of Polymer Matrix Composite Materials, ASTM International, West Conshohocken, PA, 2017, www.astm.org

22. ASTM D7264 / D7264M-15, Standard Test Method for Flexural Properties of Polymer Matrix Composite Materials, ASTM International, West Conshohocken, PA, 2015, www.astm.org 


\title{
MANUSCRIPT - 2
}

To be submitted for publication in Composites Part B: Engineering

\section{Blast Response of Carbon-Fiber/Epoxy Laminates Subjected to Long-term Seawater Exposure at Sea Floor Depth Pressures}

\author{
Dillon Fontaine ${ }^{\mathrm{a}}$; James LeBlanc ${ }^{\mathrm{b}}$; Arun Shukla ${ }^{\mathrm{a}}$ \\ ${ }^{a}$ Dynamic Photomechanics Laboratory, Department of Mechanical, Industrial and \\ Systems Engineering, University of Rhode Island, Kingston, RI 02881, USA \\ ${ }^{\mathrm{b}}$ Naval Undersea Warfare Center (Division Newport), 1176 Howell St, Newport, RI \\ 02841, USA
}

Corresponding Author: Arun Shukla, Ph.D.

Mechanical, Industrial, and Systems Engineering

University of Rhode Island

94 Upper College Rd.

Kingston, RI, 02881, USA

Email Address: shuklaa@uri.edu

Phone: +1-401-874-2283 
Abstract: An experimental investigation was carried out to determine the long term effects of exposure to a sea-floor depth ocean environment on the blast response of carbon-fiber/epoxy (CFE) laminates. By means of accelerated life testing (ALT), the behavior of laminates with and without exposure to high pressure saline water was explored using an air-blast shock tube facility and high speed stereo photography. Specimens were tested in the unweathered condition and two durations of exposure: 14 days and 24 days immersed in a $70^{\circ} \mathrm{C}, 3.5 \% \mathrm{NaCl}$ solution pressurized to $41.3 \mathrm{MPa}$ in a novel aging facility. From a diffusion study utilizing Arrhenius methodology, these cases simulate 8.9 and 15.3 years of service respectively. No statistically significant differences between the in-plane tensile elastic modulus, ultimate tensile strength, in-plane shear modulus, and ultimate shear strength were observed between any of the three cases. The flexural modulus of the laminates was observed to decrease by $13.2 \%$ and $20.8 \%$ for the two weathered cases, respectively. Dynamic air-blast experiments utilizing 3D digital image correlation (DIC) to track out-of-plane displacements revealed only marginal gains in normalized deflection of $5.1 \%$ and $2.0 \%$ for the two weathering cases, indicating no significant change in blast response with aging.

Key-words:

B - Environmental Degradation, A - Polymer-matrix composites (PMCs), A - Carbon Fibre, B - Mechanical Properties, (Optional) - Blast Response 


\section{Introduction}

In recent years, the use of composite materials for vehicles and vessels operating in marine environments has steadily increased. A review by Mouritz et al. [1] of the employment of various composite materials in surface vessels up to the beginning of the twenty-first century shows a growing interest in using these materials not only for small components such as masts and sensor coverings, but in full structural applications including framework and hull skins. Historically, composites have been known for their high stiffness-to-weight ratios, better corrosion resistance as compared to metals, and useful electrical and magnetic properties advantageous for use around sensors. In the twenty-first century, these benefits have led to the adoption of composites for use in fully submerged structures as well, such as the carbon fiber bow domes of Virginia class submarines as used by the U.S. Navy. Additionally, there is a more recent interest in unmanned underwater vehicles (UUV's) and remote operated vehicles (ROV's) which remove the operator from the vehicle thus allowing a smaller, nimbler craft that can navigate to environments and in ways manned craft cannot. With the capabilities of these vehicles determined mechanically and no longer centered on the operator, the aforementioned advantages of composites become especially desirable. There is much recent interest in forward deployed craft that operate at depths seen in the abyssal plain, where vehicles or payloads are stored for

timescales on the order of years at sea-floor depths where manned craft cannot easily venture and risk of detection is small, then are called up to the surface for actual use. Thus there is a need to understand the effect of long-term exposure to this abyssal 
environment on composite materials that are then subjected to dynamic loads at surface conditions and in the open air, including explosive loading.

The effects of long-term seawater exposure on resin systems and composites utilizing resins have previously been studied, including diffusion behavior at atmospheric pressure equivalent to surface or shallow depth exposure [2-5] and at high pressures up to 50MPa [6-10]. Rice and Romatowski [11] studied the Arrhenius temperature dependence of water ingression into polymers used as composite matrices for ALT purposes, a technique that informs the methodology used in this study. Literature surrounding the effects on diffusion are at times contradictory and sensitive to the type of polymer in question, with some finding that pressure tends to increase saturation mass yet leave diffusivity unchanged [12], while others found that both saturation mass and time to saturation increased with pressure [13].

The effects of water ingression on mechanical properties have also been studied, typically at low pressures. The compressive strength [14] and quasi-static and dynamic flexural response [15] of epoxies all showed degradation with water absorption, as did the tensile strength of polyester resins [16]. Under dynamic loading after aging at ambient pressures, the load carrying capacity of plates subjected to air blast [17] as well as the bending stiffnesses of blast and underwater explosive loaded plates [18] were all seen to decrease. Siriruk et al. [19] studied the properties of the core / face sheet interface of a composite sandwich structure, while Park et al. [20] looked at the impact performance of polymer composites, both after exposure to a marine environment. 
When considering mechanical properties after high pressure exposure, only recently have composites been considered for duties subjecting them to these pressures for durations long enough to affect them mechanically through water ingression. And though, as previously discussed, the pressure effects on diffusion have been studied, those studies primarily use only pure water without added salinity, as commercially available pressure equipment is highly sensitive to corrosion. This study aims to bridge a gap in the body of knowledge by combining the high pressures used in some diffusion studies, with the dynamic response studied only after ambient pressure weathering, all while using a saline solution to faithfully mimic ocean conditions.

\section{Materials and Methods}

\subsection{Material Fabrication and Specimen Geometry}

The composite materials used in this study were CFE panels manufactured by TPI Composites, Inc (Warren, RI), specifically for this investigation. Using the vacuum infusion method, the fundamental aspects of which are illustrated in Figure 1, panels were manufactured in two thicknesses, four ply and twelve ply. The cloth used was Saertex XC611 with a $\pm 45^{\circ}$ biaxial lay and $602 \mathrm{~g} / \mathrm{m}^{2}$ areal density. The fibers themselves were 1600tex Toho Tenax HTS40 F13, and the panels were cured under vacuum according to manufacturer's instructions in an Epikote MGS RIMR 135 / RIMH 137 resin system with a published glass transition temperature of $85^{\circ} \mathrm{C}$. 


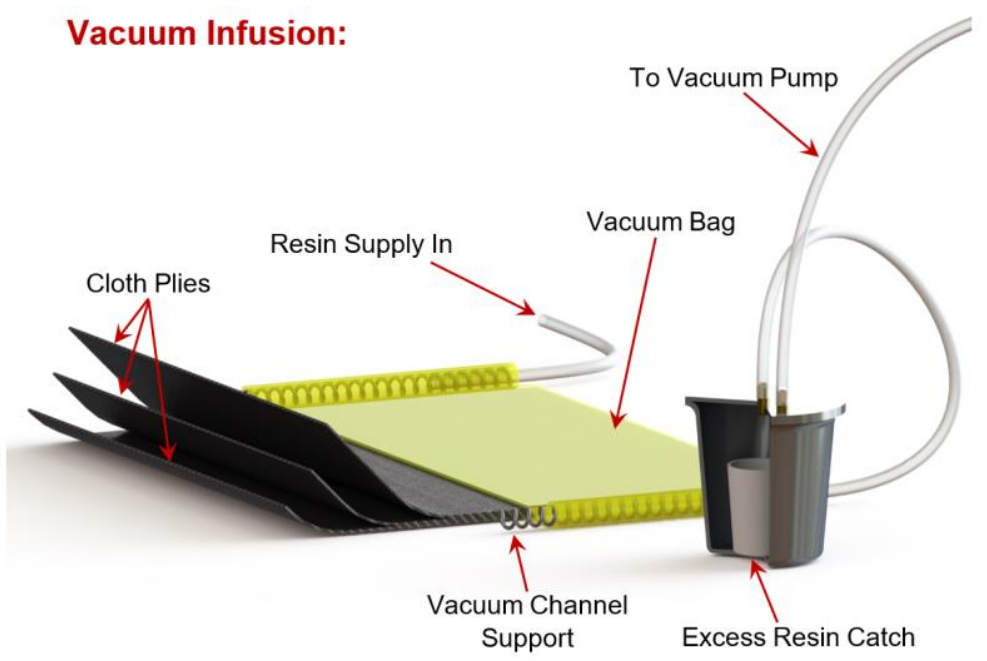

Figure 1: Schematic of the Essential Elements of Vacuum Infusion

Post-curing, burn-out tests were conducted by TPI Composites according to ASTM D2584-02 [18] which determined the fiber volume content to be $47.4 \%$ by weight.

The layups and dimensions of the various experimental geometries are given in Table 1.

Table 1: Specimen Dimensions and Layup Information

\begin{tabular}{|c|c|c|c|c|c|}
\hline & \multirow{2}{*}{ Diffusion } & \multicolumn{3}{|c|}{ Quasi-Static } & Dynamic \\
\hline & & Tension & Shear & 3 Point Bend & Air-blast \\
\hline Layup & {$[+45 /-45]_{\mathrm{s}}$} & {$[0 / 90]_{\mathrm{s}}$} & {$[+45 /-45]_{s}$} & {$[+45 /-45]_{3 \mathrm{~s}}$} & {$[+45 /-45]_{3 \mathrm{~s}}$} \\
\hline $\begin{array}{c}\text { Nominal } \\
\text { Dimensions } \\
(\mathbf{m m})\end{array}$ & $\begin{array}{c}20 \mathrm{~W} x \\
70 \mathrm{~L}\end{array}$ & $\begin{array}{l}25 \mathrm{~W} \mathrm{x} \\
178 \mathrm{~L}\end{array}$ & $\begin{array}{c}25 \mathrm{~W} x \\
216 \mathrm{~L}\end{array}$ & $\begin{array}{l}20 \mathrm{~W} \text { x 292L } \\
\text { x } 200 \mathrm{Span}\end{array}$ & $\begin{array}{c}89 \mathrm{~W} x \\
305 \mathrm{~L}\end{array}$ \\
\hline
\end{tabular}

Different layup orientations are made possible by cutting specimens at angles relative to the nominal panel coordinate system. For example, $[0,90]_{\mathrm{s}}$ is manufactured by cutting a nominally $[+45 /-45]_{\mathrm{s}}$ panel at $45^{\circ}$ with respect to an aligned edge. Prior to all aging and unweathered experiments, specimens were desiccated for at least 48 hours to remove any residual moisture. This ensured that diffusion studies and aging began 
in a moisture free state. When testing, all experiments were conducted as soon as possible after aging completed to ensure that the test was performed at the conditioned moisture content.

\subsection{Shock-tube Facility}

This investigation determined the effects of long-term seawater immersion on the blast performance of CFE composites using a shock-tube apparatus to impart a dynamic air shockwave to the mid-span of a specimen.
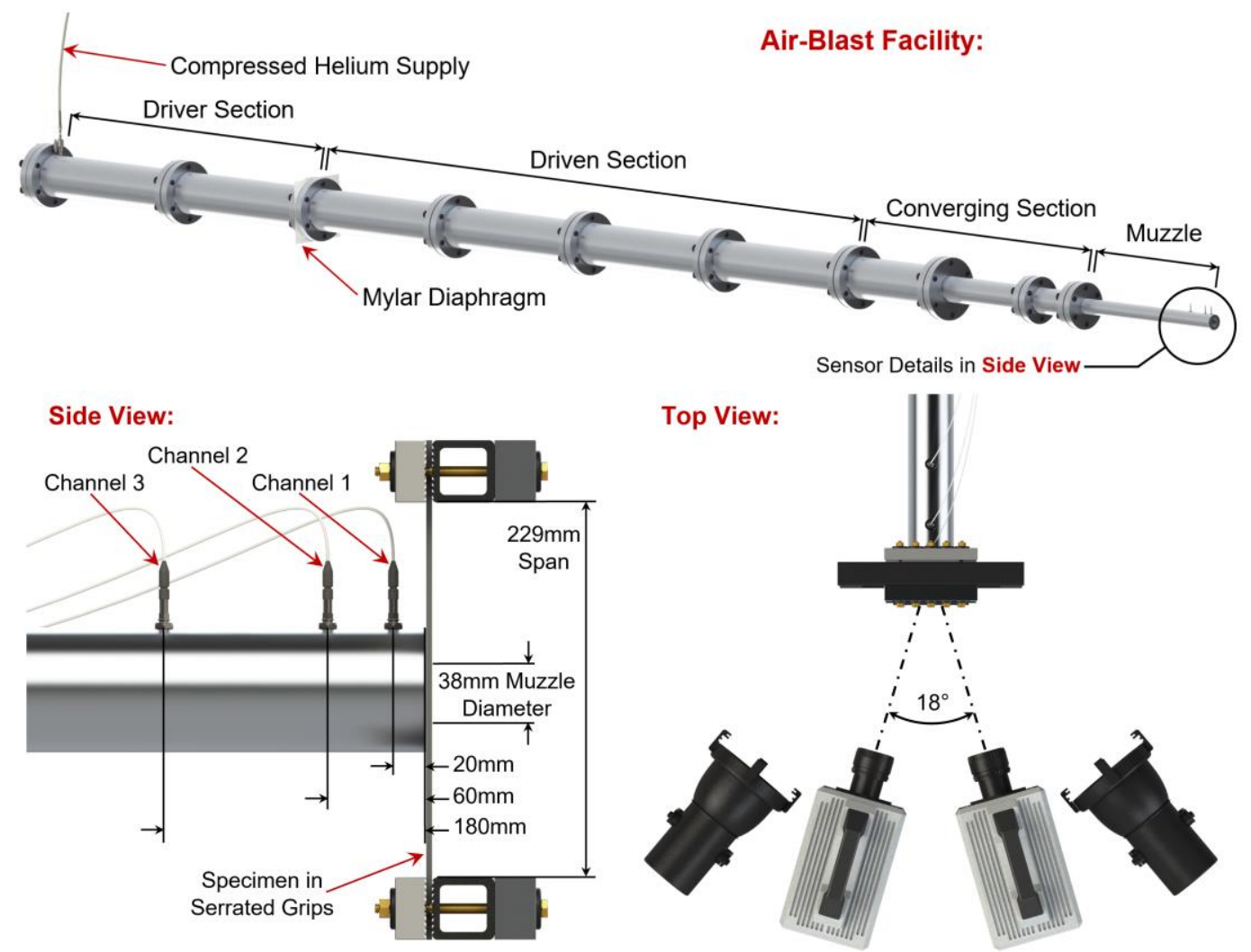

Figure 2: Air-blast Shock-tube Facility 
This apparatus is given in Figure 2. The facility is composed of an approximately $2 \mathrm{~m}$ long driver section followed by a $4 \mathrm{~m}$ long driven section, followed by a $1 \mathrm{~m}$ long tapered converging section, terminating in a $1 \mathrm{~m}$ long muzzle with an internal diameter of $38 \mathrm{~mm}$. In operation, a $0.254 \mathrm{~mm}$ mylar diaphragm is placed between driver and driven sections as shown and the former is pressurized until the diaphragm bursts. This sudden release of pressure generates a shockwave that travels the length of the apparatus, which develops into a nearly planar shock front before exiting the tube at the muzzle. The passage of the shockwave was monitored through three pressure transducer channels as shown in Figure 2, side view. Comparing data from multiple sensors allowed the speed of the shock front to be calculated, while Channel 1, the closest sensor, recorded the pressure actually imparted to the specimen. Specimens were clamped at their top and bottom ends in serrated grips to eliminate slip, leaving a $229 \mathrm{~mm}$ vertical span centered with the shock-tube axis, and placed $\sim 0.1 \mathrm{~mm}$ from the muzzle face using a feeler gauge. Illuminated by two 400W Frezzi Super Sun Guns (Frezzolini Electronics, Inc., Hawthorne, NJ), high-speed stereo photography captured by two Photron FastCam SA1.1 cameras (Photron USA., Sand Diego, CA) recorded the deflection of the back face of the specimen.

\subsection{D Digital Image Correlation}

A high contrast, random dot matrix speckle pattern was applied via paint to the back side of air-blast specimens and was recorded by stereo high-speed photography at a frame-rate of 25,000 frames per second. The speckles, black dots on a painted white background, were sized so that they occupied approximately 3-5 pixels across 
their widths in captured images. The stereo images were analyzed with VIC-3D 7 software (Correlated Solutions, Inc), which uses the calibrated geometric relationship between the two cameras to construct a three-dimensional reference frame. The speckles in each image are then grouped into uniquely identifiable subsets and tracked between concurrent stereo images and from frame to frame. The resulting output is a full-field, three dimensional deformation history of the camera-facing side of the specimens throughout the event.

\subsection{High-Pressure Accelerated Aging Facility}

In order to investigate the effects of long-term, abyssal depth ocean exposure on the blast performance of CFE composites, specimens were subjected to simulated aging in a weathering facility fabricated expressly for this purpose. The essential components of this facility are given in Figure 3.The primary component is the aging pressure vessel, which has a $15.3 \mathrm{~cm}$ diameter by $53 \mathrm{~cm}$ usable volume and is of a design and construction to handle salt water solution directly at the temperatures and pressures called for by the aging process. 


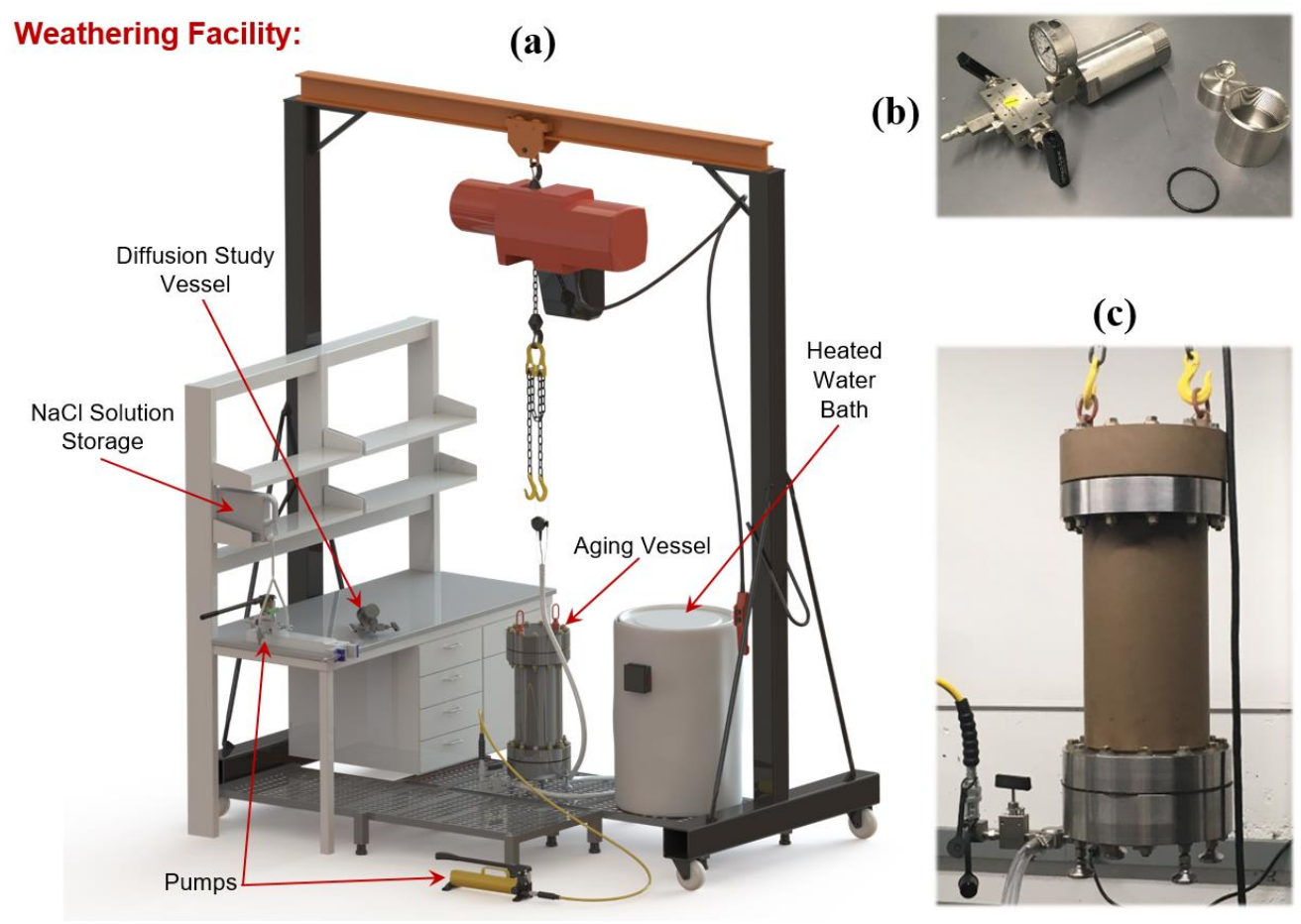

Figure 3: (a) Weathering Facility Overview; (b) Pressure Vessel Used for Diffusion Studies; (c) Pressure Vessel Used for Aging

For this study, specimens were installed in polycarbonate fixtures within the vessel to ensure all surfaces remained wetted. An example of these fixtures is shown in Figure 4. The vessel was then filled with $3.5 \% \mathrm{NaCl}$ solution and pressurized to $41.3 \mathrm{MPa}$, representative of a $4.1 \mathrm{~km}$ deep ocean. The vessel was then hoisted and immersed in a water bath maintained at $70^{\circ} \mathrm{C}$ by a BriskHeat FGDHC55120D full coverage drum heater. The control algorithm of the heater as well as the large thermal mass of the water ensured a consistent exposure temperature. 


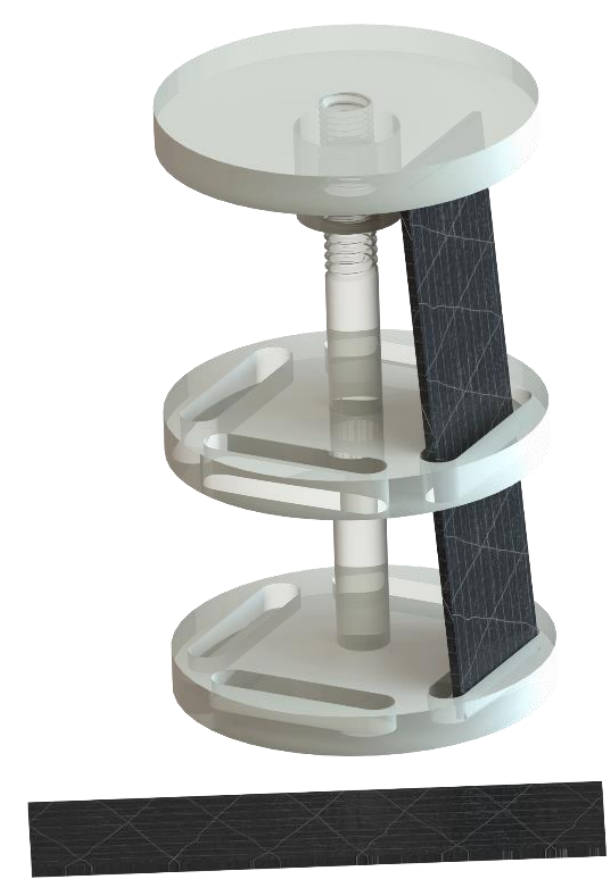

Figure 4: Example of Polycarbonate Weathering Fixture

$70^{\circ} \mathrm{C}$ was chosen because it is far enough away from the matrix glass transition temperature so as to prevent causing mechanical changes not related to water ingression yet high enough to simulate the desired time scales of exposure within a reasonable laboratory time frame. These conditions were held for two weathering cases of 14 and 24 days.

A similar procedure is used for diffusion studies albeit using the smaller pressure vessel, which was designed for ease and speed of opening and closing. Specimens were held within a polycarbonate fixture which ensured all surfaces remain wetted without touching one another or the vessel sidewalls. $\mathrm{NaCl}$ solution was added to the vessel, pressurized, and the entire vessel heated. For the diffusion study, tests were conducted at three different temperatures: 18,35 , and $65^{\circ} \mathrm{C}$. For each test, four specimens were exposed simultaneously with the percent change of the average mass 
of the batch being recorded. All specimens were desiccated for at least 48 hours prior to the beginning of aging and diffusion studies to remove residual moisture.

\subsection{Calculation of Acceleration Factor}

Previous research $[6,17,18]$ indicates that water ingression into the composite matrix is the primary mechanism of degradation. Thus the response of the composites after years of exposure in its service environment can be simulated by increasing the diffusivity of water into the specimen by raising the temperature of the high pressure saline water bath in which they are aged. This method takes advantage of the Arrhenius temperature dependence of moisture ingression in polymers to accelerate the uptake in test specimens, as shown by Rice and Romatowski [11] and others $[17,18]$. The Arrhenius relationship as it applies to the diffusivity, $D$, of water into the matrix is as follows:

$$
D=D_{0} e^{-\frac{E_{A}}{R T}}
$$

where $D_{0}$ is a constant, $R$ is the ideal gas constant, $T$ is absolute temperature, and $E_{A}$ is the activation energy of the water ingression reaction. It is assumed that the activation energy is a constant for a given material when pressure and concentration conditions are held constant, as is the case in this study. Thus, if diffusivity is quantified for a range of temperatures, the form of the Arrhenius equation allows for the calculation of the reaction rate at any temperature where the above assumptions hold.

In order to calculate diffusivity, the method of Aminabhavi et al. [22], following from the work of Crank [23] was used to determine $D$ as a function of temperature from a series of absorption curves generated at a range of temperatures. 
Three tests were performed, each with new samples, at fixed temperatures of 18,35 , and $65^{\circ} \mathrm{C}$. Samples were desiccated to ensure starting from a moisture free state, and immersed in heated and pressurized saline water baths as described in Section 2.4. The water uptake was measured gravimetrically by weighing samples periodically on a scale with precision of $10^{-4} \mathrm{~g}$. Absorption curves were then drawn from these samples. When diffusion is one dimensional and Fickian in nature, as is the case for thin, balanced, and symmetric composite strips with face areas many times larger than those of the edges, the following equation from Aminabhavi et al. [22] applies.

$$
D=\pi\left(\frac{h \theta}{4 M_{\infty}}\right)^{2}
$$

where $h$ is the thickness of each specimen, $M_{\infty}$ is the saturation percent mass gain, and $\theta$ is the initial gradient of the absorption curve obtained by plotting percent mass gain against the square root of exposure time. Here, the saturation mass gain, $M_{\infty}$, is specific to the material and is independent of temperature. This allows carrying only one test, in this case at the highest temperature, to saturation, and the other tests may be continued only as long as is necessary to accurately characterize the initial rise of the absorption curve. With diffusivity calculated for various temperatures, Equation 1 can be recast as follows:

$$
\ln (D(T))=\ln \left(D_{0}\right)-\left(\frac{E_{A}}{R}\right)\left(\frac{1}{T}\right)
$$

with emphasis on diffusivity being dependent on temperature and its natural logarithm being linear with the inverse of temperature, the linear factor being the activation energy normalized by the ideal gas constant. The acceleration factor, $A F$, can now be 
defined as the ratio between diffusivity at an elevated temperature, $D_{2}$ at $T_{2}$, and that at a reference temperature, $D_{\text {ref }}$ at $T_{\text {ref }}$, as follows:

$$
A F=\frac{D_{0} e^{-\frac{E_{A}}{R T_{2}}}}{D_{0} e^{-\frac{E_{A}}{R T_{\mathrm{ref}}}}}=e^{\left(\frac{E_{A}}{R}\right)\left(\frac{T_{2}-T_{\mathrm{ref}}}{T_{2} * T_{\mathrm{ref}}}\right)}
$$

For this study, $T_{\text {ref }}$ is taken to be $3.0^{\circ} \mathrm{C}$, the commonly accepted value for seawater in the abyssal plain.

\subsection{Quasi-static Testing}

Coupons were cut from the CFE panels in dimensions described in Table 1, which conform as closely as practical to the guidelines established in ASTM D3039M-14 [24] for tensile coupons, ASTM D3518M-13 [25] for in-plane shear coupons, and ASTM D7264-15 [26] for three point bend coupons. Coupons were desiccated prior to either unweathered testing or aging, and aged specimens were tested as soon as possible after aging and not more than 24 hours to ensure negligible loss of moisture post-aging. Testing was done using an Instron Model 5585 equipped with a $200 \mathrm{kN}$ load cell. Full field in-plane strain data was obtained using 2D digital image correlation, a variant of 3D DIC using only one camera that captures strains only within the plane of the specimen and not through the thickness. Digital load data and images were synchronously captured at a rate of one sample per second throughout the duration of the tests. By being able to interrogate the entire strain field of each specimen, more accurate data may be collected than discrete strain gages, as a true average of strain can be collected while also verifying that the data is free of the 
corrupting effects of stress concentration at the grips and point of failure that do not accurately reflect the bulk material response.

\section{Experimental Results and Discussion}

CFE specimens were artificially aged in a heated, pressurized saline water bath to simulate real world service times on the order of years. A diffusion study conducted at the same pressure as in aging was conducted to determine the acceleration factor and thus the real world equivalent time simulated by the weathering. The flexural and in-plane tensile and shear properties of the laminates were characterized in the unweathered case and after two durations of accelerated aging. The dynamic response of fixed-fixed CFE beams subjected to air blast loading at midspan was also investigated for the same three weathering cases.

\subsection{Results of Diffusion Study}

For each test, four specimens were immersed in saline solution pressurized to 41.3MPa and maintained at the test temperature, and the average mass gain of the group at each time sample was plotted to create the absorption curves. To enable the use of Equation 2 to calculate the diffusivity at each temperature, the curves are shown plotted against the square root of exposure time, as shown in Figure 4a. Then, to obtain the activation energy through the use of Equation 3, linear regression was performed on a plot of the natural logarithm of each test's diffusivity against the inverse of the corresponding exposure temperature, which is shown in Figure 4b. A saturation mass gain of $0.96 \%$ was reached by the $65^{\circ} \mathrm{C}$ test after approximately 1000 
hours of exposure. This saturation value was assumed to be a constant for this material at the fixed hydrostatic pressure. From these plots, and with a reference temperature of $3.0^{\circ} \mathrm{C}$ and hydrostatic pressure of $41.3 \mathrm{MPa}$, the acceleration factor for the $\mathrm{CFE}$ laminates was determined to be $0.64 \mathrm{yr} / \mathrm{day}$.
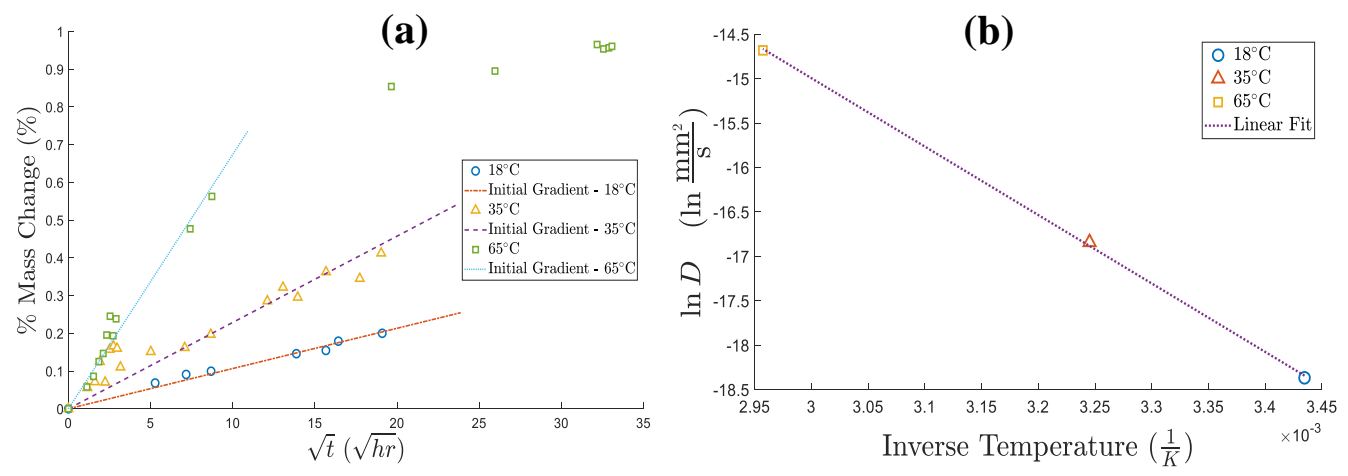

Figure 5: (a) Absorption Curves; (b) Determining Activation Energy from the natural $\log$ of Diffusivity

This resulted in the 14 and 24 day weathering cases simulating 8.9 and 15.3 years of real world service exposure, respectively.

\subsection{Results of Quasi-Static Testing}

Quasi-static testing was performed to ascertain the bulk in-plane tensile and shear as well as flexural properties of the CFE laminates for the unweathered, 14 day, and 24 day weathered cases.

Interestingly, and unlike prior research with similar materials weathered in similar ways only without the added pressure component, no significant differences were observed between any of the three cases in either tensile or shear moduli and ultimate strengths. The results of the testing are tabulated in Table 2. 
Table 2: Quasi-static Summary Table

\begin{tabular}{|c|c|c|c|c|}
\hline $\begin{array}{c}\text { Weathering } \\
\text { Time }\end{array}$ & $\begin{array}{c}\text { Tensile } \\
\text { Modulus } \\
\text { (GPa) }\end{array}$ & $\begin{array}{c}\text { Ultimate } \\
\text { Tensile } \\
\text { Strength (MPa) }\end{array}$ & $\begin{array}{c}\text { Tensile } \\
\text { Strain at } \\
\text { Failure }(\%)\end{array}$ & $\begin{array}{l}\text { Flexural } \\
\text { Modulus } \\
\text { (GPa) }\end{array}$ \\
\hline Unweathered & 71.9 & 813 & 1.03 & 13.9 \\
\hline 14 days & 73.0 & 809 & 1.13 & 12.1 \\
\hline \multirow[t]{2}{*}{24 days } & 72.6 & 807 & 1.20 & 11.0 \\
\hline & $\begin{array}{c}\text { Shear } \\
\text { Modulus } \\
\text { (GPa) }\end{array}$ & $\begin{array}{l}\text { Ultimate Shear } \\
\text { Strength (MPa) }\end{array}$ & $\begin{array}{c}\text { Shear Strain } \\
\text { at Failure } \\
(\%)\end{array}$ & \\
\hline Unweathered & 2.55 & 50.6 & 13.4 & \\
\hline 14 days & 2.61 & 46.1 & 13.5 & \\
\hline 24 days & 2.50 & 45.6 & 13.9 & \\
\hline
\end{tabular}

Interestingly, and unlike prior research with similar materials weathered in similar ways only without the added pressure component, no significant differences were observed between any of the three cases in either tensile or shear moduli and ultimate strengths, although flexural modulus was observed to significantly decrease by $13.2 \%$ and $20.8 \%$ after 14 and 24 days, respectively. This is thought to be the result of hydrostatic pressure closing micro-voids at the fiber / matrix interface. As a natural consequence of the vacuum infusion process, the matrix is thought to set up in "bands" in between plies. The fibers within each ply are tightly packed leading to through thickness striations as shown exaggerated in Figure 6b. Pressure and its compressing effects on the matrix may force ingressed water to concentrate within the bands in between plies, thus leaving the in-plane properties relatively unchanged yet still causing the characteristic degradation to occur for interlaminar properties, which the flexural modulus is dominated by. 


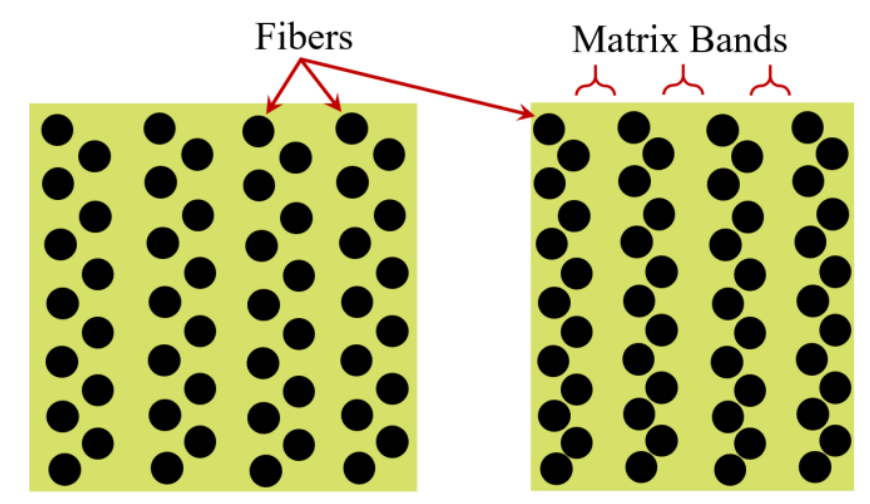

(a)

(b)

Figure 6: Cross-Fiber Section Schematic of Vacuum Infused Composite with Unwoven Plies at (a) Ambient Pressure and (b) High Hydrostatic Pressure

Because the penetrant water molecules have a finite size which the matrix must accommodate in order to absorb them and the fibers are relatively incompressible, pressure has the effect of forcing fibers together without changing their size, decreasing the probability of opening a proper size void to accept penetrant at these locations.

\subsection{Air-Blast Response}

The blast response of the CFE laminates was investigated by imparting an air shockwave onto the midspan of a fixed-fixed beam specimen using a shock tube apparatus. The typical loading curve is presented in Figure 7, as recorded by a pressure transducer located 20mm from the muzzle section exit (Channel 1, Figure 2). The curve is characterized by an incident shock pressure at approximately $250 \mu$ s, recorded before the shock front reaches the specimen, followed by a much higher reflected pressure as the shockwave rebounds from the specimen face. Time $t=0$ was chosen to be the point when the earliest channel (Channel 3, Figure 2) experiences a 
pressure rise, a useful reference for synchronizing data acquisition. Pressure rise times are on the order of tens of microseconds, and it should be noted that the reflected pressure is what is actually imparted to the specimen. The pressure decays exponentially to zero and typically experiences three defined peaks before doing so. This oscillatory nature is mirrored in the deflection profiles of the specimens, which occurs as a result of the vibration of the beam interacting with the venting gas after the shock front passes. As the beam bends away from the muzzle, out-flow become less constricted and pressure decreases. Conversely, as the beam bends back towards the muzzle, flow is restricted and pressure increases. This can be seen by noting that the pressure curves in Figure 8 have local maxima whenever the deflection curves have local minima, and vice versa. By recording the point in time the pressure initially rises from zero for each of the pressure channels shown in Figure 2 and noting the distance between each channel, the speed of the shockwave just before impact can be calculated, typically presented as a multiple of the speed of sound in air $(343 \mathrm{~m} / \mathrm{s})$, or Mach number. 


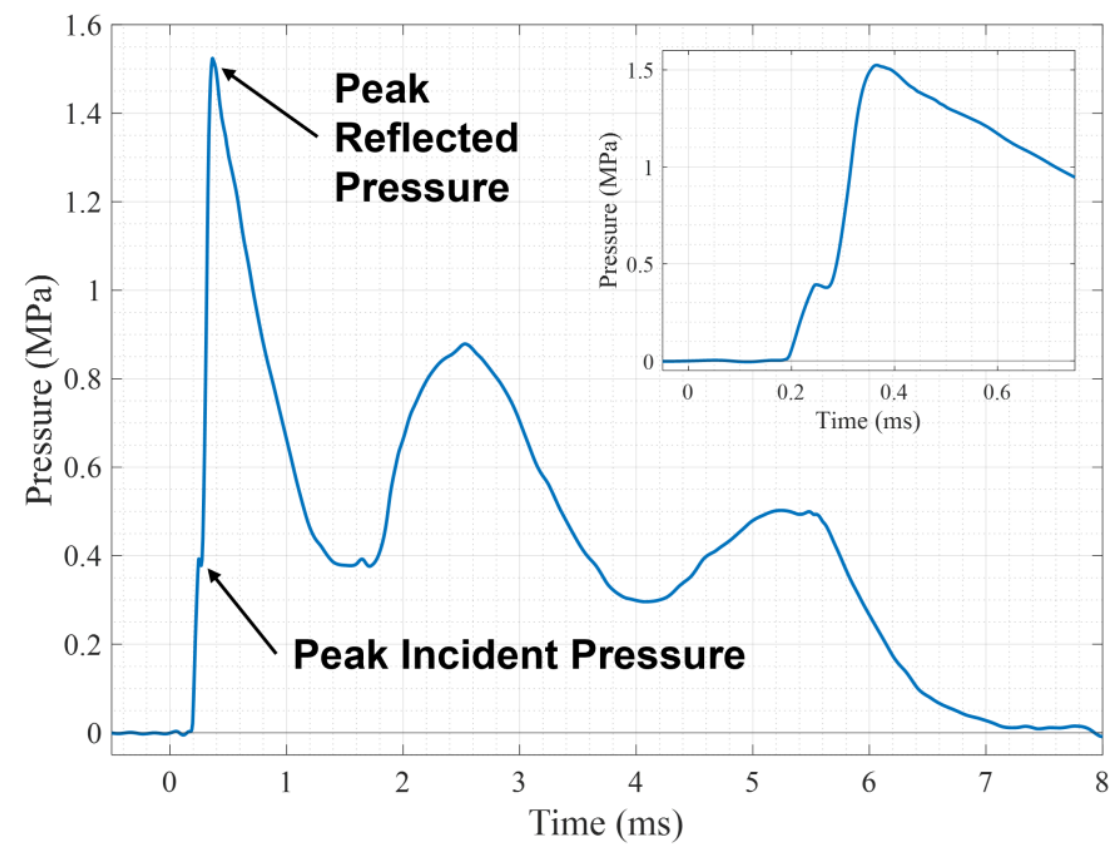

Figure 7: Typical Loading Curve for the Shock Tube Facility with 0.254mm Diaphragm

The average incident shock wave Mach numbers for each weathering case showed little variation and were $2.43,2.41,2.37$ for the unweathered, 14 day, and 24 day cases respectively. Pressure histories for three representative experiments are given as the dotted curves in Figure 7. It should be noted that although there are slight differences in the speed of the incident shockwave, incident pressures remained consistent between weathering cases and peak reflected pressure showed good agreement on average.

Full field out of plane displacements of the beams were recorded using 3D DIC. The center point displacements, which are typically the maximum the beams experience, are plotted as the solid curves in Figure 8 for three representative experiments, one for each weathering case. For verification, the unweathered 
experiments and each weathered case were repeated three times; all showed similar general behavior as well as peak out of plane displacements within each case.

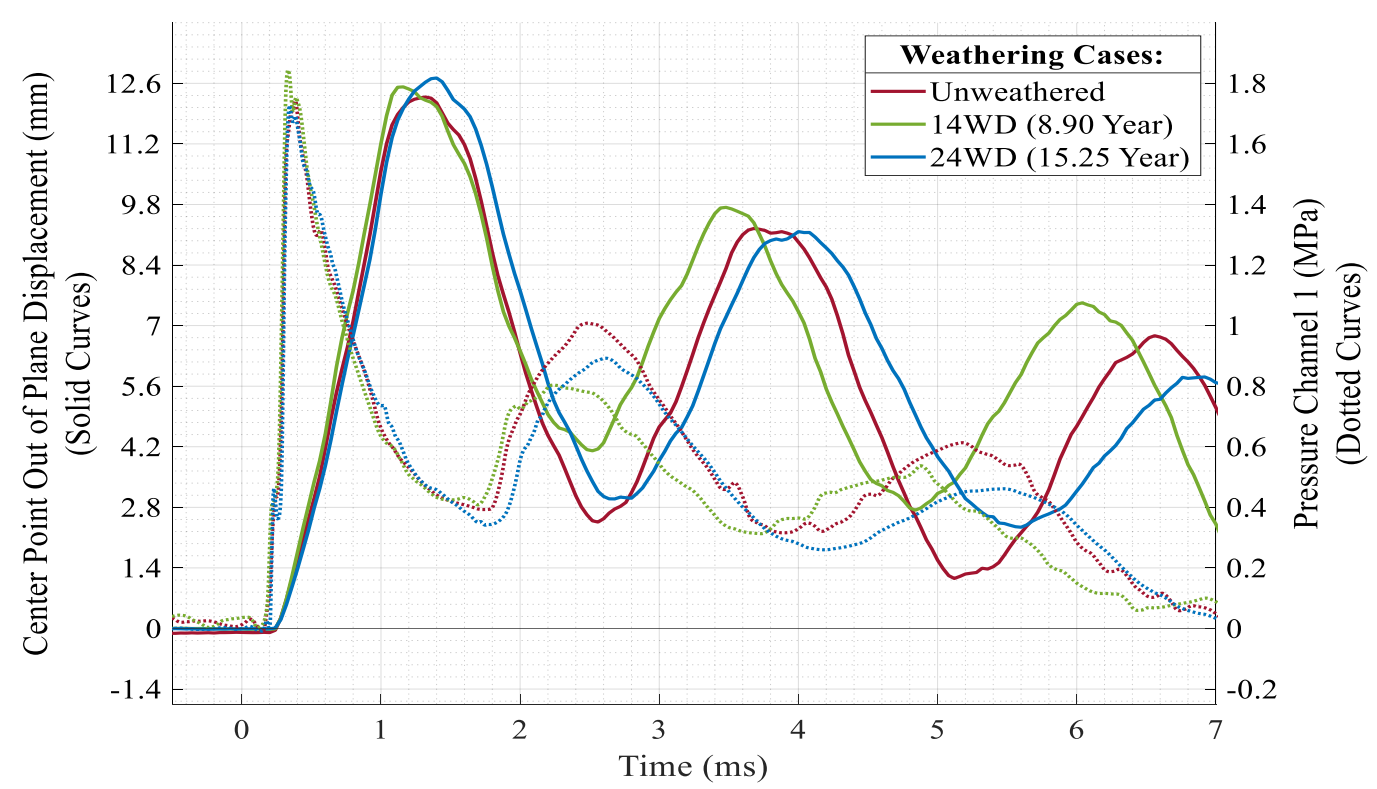

Figure 8: Representative Center Point Out of Plane Displacement Histories for the Three Weathering Cases

From the pressure curves of Figure 8, it can be seen that there are slight variations in the reflected pressure histories, particularly the peak reflected pressures, thought to be inherent variation in the shock tube most likely caused by the bursting mechanics of the mylar diaphragm or small variations in the muzzle standoff, to which the reflected pressure is highly sensitive. These variations are not thought to be a result of aging, as reflection of the wave naturally occurs before the material has time to respond.

Nevertheless, these variations constitute differences in the loadings, which must be accounted for if viable comparisons are to be drawn. 
The out of plane deflection of the beams is driven by the impulse transferred due to the net pressure acting on the beam as recorded by Channel 1, given by Wang et al. [27] as the integral of the reflected pressure profile, as follows:

$$
I(t)=\int_{0}^{t}\left(p(\tau)-p_{0}\right) d \tau
$$

This duration of interest is taken to be from the beginning of the reflected pressure profile at approximately $\mathrm{t}=300 \mu \mathrm{s}$ to the time the specimen takes to reach its peak deflection, or approximately until $\mathrm{t}=1.5 \mathrm{~ms}$, although the linear relationship may be valid even longer. Also, if this linear relationship between impulses is valid for a group of tests individually compared to some reference, then the relationship will also hold for any test in the group compared to any other test in the group, by the definition of a linear map. Let a factor $Q$ represent the ratio of impulses between two pressure signals within a duration of interest $t_{0}$ to $t_{1}$, where the signals have been synchronized about $t_{0}$, as follows:

$$
Q=\frac{\mathrm{I}_{\mathrm{n}}(t)}{I_{\mathrm{ref}}(t)}
$$

where $I$ is defined as in Eq. 5. The subscript " $n$ " represents the test of interest, while “ref' denotes a reference test. Because pressure is a time varying signal, so too is $Q$. If $Q$ is a constant value in the duration of interest, the impulse delivered to the specimen at every instant in this duration in one test is a simple linear scaling of the other test. Let this linear scale be denoted by $\bar{Q}$.The impulse curves were calculated using numerical integration of the pressure curves in Figure 8 and Eq. 5 and are shown as the solid curves in Figure 9. The dashed curves represent the instantaneous values of the $Q$ factors of the two weathered cases taken with respect to the unweathered case. 
As can be seen from this graph, each weathered test's $Q$ settles quickly to a near constant value after $\mathrm{t}=400 \mu \mathrm{s}$, showing some nonlinearity briefly at the beginning of the curve. These nonlinearities can safely be ignored as they are small in magnitude and only occur when impulse is very small with respect to its final value, and thus their effects on specimen deformation are negligible. The value of $\bar{Q}$ for each weathered test is tabulated in Table 3, calculated by averaging the $Q$ curve over the region of relative constancy from $\mathrm{t}=400 \mu$ s onwards.

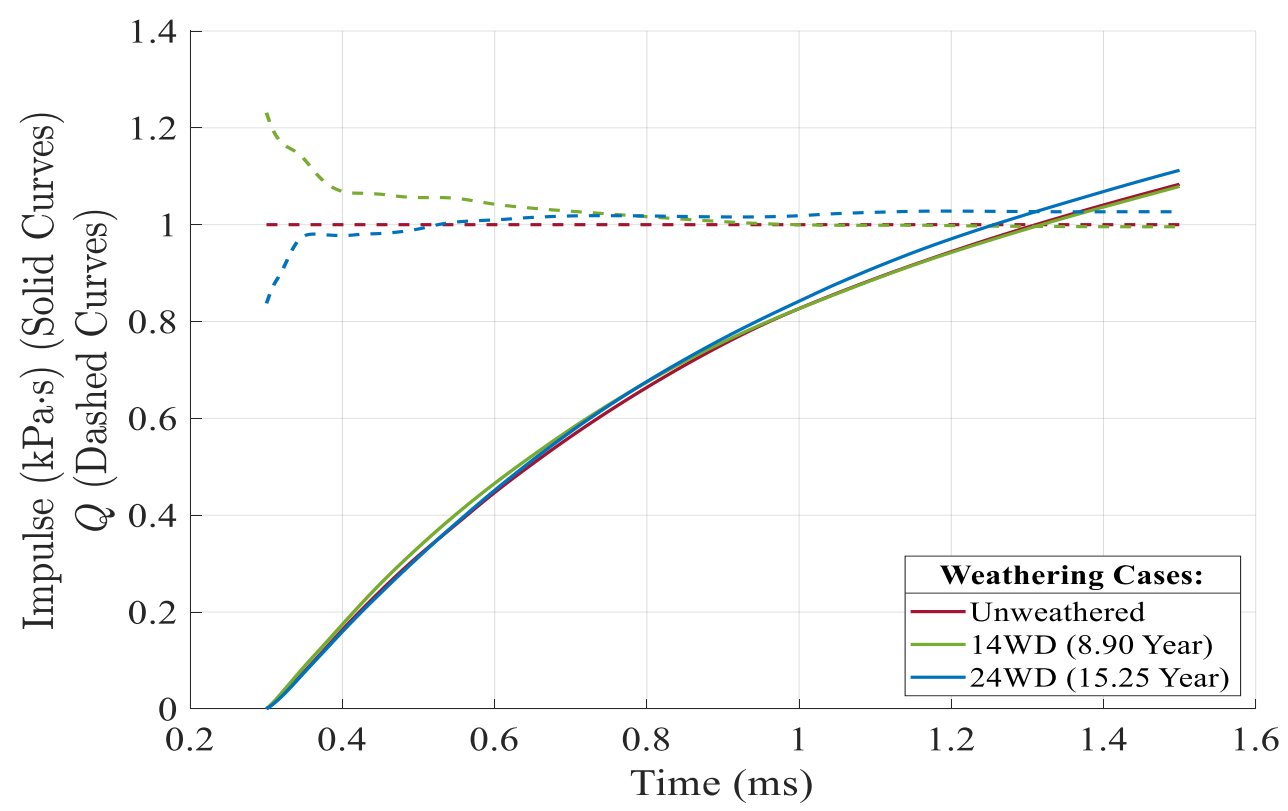

Figure 9: Impulse and $Q$ Curves for the Three Weathering Cases

Because specimen geometry, areal density, and the fixed-fixed boundary conditions remained the same for all tests; all beams deformed elastically; and the impulses imparted to the beams were previously shown to be linear mappings of each other, the peak deflections of the center point of the beams may be considered to vary directly as a function of the magnitude of the applied impulse and the beam's resistance against deformation. Thus the existence of the $\bar{Q}$ factor and the linear 
relationship it implies allows a relative comparison to be made between peak deflections which immediately illustrates any differences in response characteristics. Let $D$ represent the response factor, a form of normalized deflection, as follows:

$$
D=\frac{d_{n, p e a k}}{\bar{Q} * d_{\text {ref,peak }}}
$$

where $\bar{Q}$ is understood to be taken between the $n^{\text {th }}$ test and the reference. It follows from Eq. 6 that this non-dimensional term represents the relative response of the specimen with respect to the reference and evaluates to unity for the reference test by definition. For a specific test, a higher $D$ value than a reference indicates more response for the same input and thus less of the shock loadings is mitigated through stiffness or viscous effects. It should be noted that this normalization procedure is valid in this case only because the architecture of the material was identical between tests and geometric and mass properties of the beams were effectively constant throughout. If this not true, a different method for comparison would be required. However, an approach based on impulse and deflection was selected because these values follow directly from the measurable quantities in each experiment, with numerical manipulation only required in the form of integration of the pressure signal.

Table 3: Peak Pressures and Non-Dimensional Parameters for the Three Weathering Cases

\begin{tabular}{|c|c|c|c|c|}
\hline $\begin{array}{c}\text { Weathering } \\
\text { Case }\end{array}$ & $\begin{array}{c}\text { Peak Reflected } \\
\text { Pressure (MPa) }\end{array}$ & $\overline{\boldsymbol{Q}}$ & $\boldsymbol{D}$ & $\begin{array}{c}\text { \% } \\
\text { Increase } \\
\text { in } \boldsymbol{D}\end{array}$ \\
\hline Unweathered & 2.26 & 1 & 1 & - \\
\hline 14 day & 1.84 & 0.842 & 1.044 & +4.4 \\
\hline 24 day & 1.53 & 0.758 & 1.052 & +5.2 \\
\hline
\end{tabular}


The response factor values calculated in this way are included in Table 3, where the third unweathered experiment was chosen arbitrarily as the reference, as the percent changes in $D$ are independent of the choice of reference. Unlike prior studies with CFE laminates subjected to long-term saline exposure, which differ from this study primarily in the pressure of the solution during aging, the beams did not display significantly different behavior as a result of blast loading. The normalized deflections only show marginal gains of $5.1 \%$ and $2.0 \%$ for the 14 day and 24 day weathering cases, respectively. These values are within the limits of the normalization method to detect differences in stiffness and illustrate a significant departure from the magnitudes of degradation normally associated with moisture ingression. However, this is consistent with the findings in quasi-static in-plane properties. Also, because much of the load in a fixed-fixed beam is transferred to tension within the plies, it is reasonable that out of plane deflections remain relatively constant when tensile and shear moduli do not change, despite the observed decrease in flexural modulus.

\section{Conclusions}

A series of experiments were conducted to evaluate the effects on blast performance of carbon-fiber / epoxy composites subjected to saline water exposure simulating years of storage in the abyssal depth ocean. Using accelerated life cycle methods, a diffusion study was performed to create absorption curves and measure the dependence of diffusivity with exposure temperature, thus allowing a quantitative relationship to be drawn between exposure in the lab and service exposure. It was determined that the significant degradation seen in other studies that did not use a 
pressurized aging solution is not present in this study, both under quasi-static and dynamic loadings. The specifics of the results may be summarized as follows:

- The acceleration factor representing the ratio of real world service time to lab exposure time was determined to be $0.64 \mathrm{yr} / \mathrm{day}$, when using a reference service temperature of $3.0^{\circ} \mathrm{C}$ and when exposed to $41.3 \mathrm{MPa}$ saline water.

- The quasi-static in-plane tensile and shear moduli, ultimate tensile and shear strengths, and tensile and shear strains at failure did not significantly change after 14 and 24 days of weathering at $70^{\circ} \mathrm{C}$ (simulating 8.90 and 15.3 years of exposure).

- Fixed-fixed beams subjected to 0,14 , and 24 days of weathering were loaded at the center of a $229 \mathrm{~mm}$ span by a shock tube apparatus. High frequency response pressure transducers recorded the loading on the front face while high speed stereo cameras utilizing 3D DIC recorded back face deflections. All beams deformed and recovered elastically.

- Using an impulse based normalization method, the normalized center point out-of-plane deflections for the unweathered, 14, and 24 day weathering cases were $0.98,1.03$, and 1.00 , respectively. These values show that the blast response of the beams changes negligibly with aging.

- The large decrease in flexural stiffness with aging combined with the relative constancy of in-plane properties and normalized shock response were thought to be the result of the large hydrostatic pressure closing micro-voids at the fiber / matrix interface and forcing water ingression to occur primarily at the regions of 
resin in between plies. In this way, ingression still occurs while the matrix within each ply remains relatively undamaged.

Acknowledgments

The authors would like to kindly thank Dr. Maria Medeiros from the Office of Naval Research for financial support under Grant No. N00014-18-1-2641, as well as colleagues at the Dynamic Photomechanics Laboratory, especially Anthony Marshall, Tyler Chu, and Irine Chenwi, whose help proved indispensable during this study. The authors are also grateful for the assistance of TPI Composites, particularly Tim Fallon, Mike Trapela, and their group, who graciously oversaw the fabrication of material for this study.

\section{References}

1. Mouritz, A. P., Gellert, E., Burchill, P., \& Challis, K. (2001). Review of advanced composite structures for naval ships and submarines. Composite structures, 53(1), 21-42.

2. Tucker, W., Lee, S., \& Rockett, T. (1993). The effects of pressure on water transport in polymers. Journal of Composite Materials, 27(8), 756-763. Retrieved from http://jcm.sagepub.com/content/27/8/756.

3. Xu, L., Krishnan, A., Ning, H., Vaidya, U., A seawater tank approach to evaluate the dynamic failure and durability of E-glass/vinyl ester marine composites, Composites Part B: Engineering, 43(5), 2012, 2480-2486, https://doi.org/10.1016/j.compositesb.2011.08.039. 
4. Deniz, M., Ozen, M., Ozdemir, O., Karakuzu, R., Icten, B., Environmental effect on fatigue life of glass-epoxy composite pipes subjected to impact loading, Composites Part B: Engineering, 44(1), 2013, 304-312, https://doi.org/10.1016/j.compositesb.2012.05.001.

5. Nicholas, J., Mohamed, M., Dhaliwal, G.S., Anandan, S., Chandrashekhara, K., Effects of accelerated environmental aging on glass fiber reinforced thermoset polyurethane composites, Composites Part B: Engineering, 94, 2016, 370-378, https://doi.org/10.1016/j.compositesb.2016.03.059.

6. Le Gac, P.-Y., Davies, P., \& Choqueuse, D. (2015). Evaluation of Long Term Behaviour of Polymers for Offshore Oil and Gas Applications. Oil \& Gas Science and Technology - Revue d'IFP Energies Nouvelles, 70(2), 279-289. https://doi.org/10.2516/

7. Cartié, D., Davies, P., Peleau, M., Partridge, I. K., The influence of hydrostatic pressure on the interlaminar fracture toughness of carbon/epoxy composites, Composites Part B: Engineering, 37(4-5), 292-300, https://doi.org/10.1016/j.compositesb.2005.12.002.

8. Humeau, C., \& Davies, P. (2015). Moisture diffusion under hydrostatic pressure in composites, Materials \& Design, 96(July), 19

9. Pollard, A., Baggott, R., Wostenholm, G. H., Yates, B., \& George, A. P. (1989). Influence of hydrostatic pressure on the moisture absorption of glass fibre-reinforced polyester. Journal of Materials Science, 24(5), 1665-1669. https://doi.org/10.1007/BF01105689 
10. Chen, S., Xu, H., Duan, H., Hua, M., Wei, L., Shang, H., \& Li, J. (2017).

Influence of hydrostatic pressure on water absorption of polyoxymethylene: experiment and molecular dynamics simulation. Polymers for Advanced Technologies, 28(1), 59 $\square 65$. https://doi.org/10.1002/pat.3858

11. Rice, M., \& Ramotowski, T. (2011). Activation energy calculation for the diffusion of water into PR-1590 and pellethane 2103-80AW polyurethanes. NUWC-NPT Technical Memo, 11-062.

12. Tucker, W. C., \& Brown, R. (1989). Moisture Absorption of Graphite / Polymer Composites Under 2000 Feet of Seawater, Journal of Composite Materials, 23(8), 787-797 https://doi.org/10.1177\%2F002199838902300802

13. Pilli, S. P., \& Smith, L. V. (2012). The effect of pressure on moisture diffusion in polymer matrix composites. International Journal of Thermophysics, 33(89), 1715-1725. https://doi.org/10.1007/s10765-012-1329-3

14. Kishore, Barpanda, P., \& Kulkarni, S. M. (2005). Compression strength of saline water-exposed epoxy system containing fly ash particles. Journal of Reinforced Plastics and Composites, 24(15), 1567-1576. https://doi.org/10.1177/0731684405050390

15. Papanicolaou, G. C., Kosmidou, T. V., Vatalis, A. S., \& Delides, C. G. (2006). Water absorption mechanism and some anomalous effects on the mechanical and viscoelastic behavior of an epoxy system. Journal of Applied Polymer Science, 99(4), 1328-1339. https://doi.org/10.1002/app.22095

16. Nacher, L. S., Amoros, J. E. C., Moya, M. D. S., \& Martinez, J. L. (2007). Mechanical Properties of Polyester Resins in Saline Water Environments. 
International Journal of Polymer Analysis and Characterization, 12(5), $373 \square 390$. https://doi.org/10.1080/10236660701516557

17. Shillings, C., Javier, C., LeBlanc, J., Tilton, C., Corvese, L., \& Shukla, A. (2017). Experimental and computational investigation of the blast response of Carbon-Epoxy weathered composite materials. Composites Part B:

Engineering, 129, 107-116. https://doi.org/10.1016/j.compositesb.2017.07.023

18. Matos, H., Javier, C., LeBlanc, J., \& Shukla, A. (2018). Underwater nearfield blast performance of hydrothermally degraded carbon-epoxy composite structures. Multiscale and Multidisciplinary Modeling, Experiments and Design, 1(1), 33-47. https://doi.org/10.1007/s41939-017-0004-6

19. Siriruk, A., Penumadu, D., \& Weitsman, Y. J. (2009). Effect of sea environment on interfacial delamination behavior of polymeric sandwich structures. Composites Science and Technology, 69(6), 821-828.

20. Park, S. W., Veazie, D. R., \& Zhou, M. (2000, May). Post-impact aging of FRP composite laminates in the marine environment. In Proceedings of the 14th engineering mechanics conference, Austin, TX.

21. ASTM D2584-02, Standard Test Method for Ignition Loss of Cured Reinforced Resins, ASTM International, West Conshohocken, PA, 2002, www.astm.org

22. Aminabhavi, T. M., Thomas, R. W., \& Cassidy, P. E. (1984). Predicting water diffusivity in elastomers. Polymer Engineering \& Science, 24(18), 1417-1420.

23. Crank J. 2nd ed. The mathematics of diffusion UK: Oxford University Press; 1975.ISBN-13: 978-019853411 
24. ASTM D3039 / D3039M-17, Standard Test Method for Tensile Properties of Polymer Matrix Composite Materials, ASTM International, West Conshohocken, PA, 2017, www.astm.org

25. ASTM D3518 / D3518M-18, Standard Test Method for In-Plane Shear Response of Polymer Matrix Composite Materials by Tensile Test of a $\pm 45^{\circ}$ Laminate, ASTM International, West Conshohocken, PA, 2018, www.astm.org

26. ASTM D7264 / D7264M-15, Standard Test Method for Flexural Properties of Polymer Matrix Composite Materials, ASTM International, West Conshohocken, PA, 2015, www.astm.org

27. Wang, E., Wright, J., Shukla, A. (2011). “Analytical and experimental study on the fluid structure interaction during air blast loading," Journal of Applied Physics, 110(11), https://doi.org/10.1063/1.3662948 


\section{APPENDICES}

Appendix 1. Introduction, Review of the Problem, and Motivation

This Appendix is intended as a summary of introductory and motivating remarks from the preceding manuscripts.

This work experimentally investigated the mechanical behavior of carbon-fiber composite materials after simulated exposure to a sea-floor depth ocean environment for time scales on the order of years. For decades, the advantages of composite materials, particularly their high strength- and stiffness-to-weight ratios, corrosion resistance, and electromagnetic properties have seen them used in many military applications, including heavy use in maritime applications. While the majority of naval usage takes place at the ocean surface or in shallow depths, such as for components of ships and small patrol craft, and the effects of this service environment on mechanical behavior has been well studied, there is recent demand to leverage the advantages of composites in deep sea applications. The deep ocean represents the largest expanse of freely traversable space on Earth, and in the interest of both exploration and military defense, this space must be made accessible. However, the behavior of these advanced and relatively new materials after long term exposure to this environment remains unknown, and so informed design is nearly impossible and based primarily on speculation and assumptions that surface effects scale with depth. In the interest of efficiency and reliability of design, these changes in behavior, if they do exist, must be studied and quantified, and that is the effort of this work.

The primary challenge in accomplishing this goal is the ability to create an environment that accurately simulates the deep ocean for the proper combinations of 
pressure, temperature, and time that are necessary for a useful study. Obviously, when effects are sought for exposure times on the order of a decade, it is impractical to naturally age for these time scales. Fortunately, the accelerated life testing (ALT) methods used in the study of surface exposure effects have been shown to be applicable to the deep ocean environment. In the context of aging composite materials, ALT trades long time constraints for high temperature conditions, and so now the problem has been transformed to one of maintaining sea-floor depth pressures at elevated temperatures. However, this poses yet another challenge, as commercially available pressure equipment was deemed insufficient for this application. The primary detractor was the issue of corrosion, as the salt in ocean water would quickly destroy even the exotic materials used in some pressure vessels. Thus the overall effort of this work has been stratified into two goals, one which depends upon the success of the other. Firstly, there is a need for a novel pressurized aging facility that is capable of creating the necessary environment for useful ALT. Secondly, well controlled experiments must be carried out on specimens that have been exposed to this environment for various times in order to compare how the environment has impacted characteristic mechanical properties and responses to the type of loads that will likely be faced in service.

The first manuscript explores in detail the design of a pressurized aging facility designed to meet the requirements of the first goal. This facility constituted a novel design and an advance in ALT technology, and as of this writing, the protection of a patent has been sought for the technology contained therein. The second manuscript describes the experimental approach used for the comparison set forth by the second 
goal. The work as it will be published is concerned primarily with quasi-static material characterization and dynamic flexural response and air-blast loading, although efforts are ongoing to study a full range of responses to loadings these materials are likely to face. 
Appendix 2. Speculative Discussion and Implications of the Work

This Appendix is intended as a summary of discussion and concluding remarks from the preceding manuscripts.

The goal of this work was to establish and implement a method for investigating the mechanical properties of composite materials that have been exposed to a sea-floor depth environment for times on the order of years approaching decades. For reasons of practicality, these time scales necessitated accelerated life testing, and due to the complicating factors of salt water, pressure, temperature, and time, this necessitated a novel approach to pressure vessel design for a system that could survive in the presence of highly corrosive media. To this end, a design was fabricated and tested successfully which utilized a nitrile diaphragm to transfer pressure from an inert hydraulic oil domain into a volume of seawater containing the test specimens. The interior of this volume was coated in an inert Cerakote ceramic infused resin which possessed the necessary corrosion resistance and mechanical properties required for such service. By using a diaphragm isolator, only the static seals and coated metallic parts came into contact with the corrosive saline media; pressure generating, monitoring, and relief systems were isolated on the oil side where there was no risk of corrosion. Reinforcement of the diaphragm by internally woven nylon cloth was shown to be sufficient to ensure repeatability and reliability of the system. Some thermal degradation and seal deterioration due to softening were shown where the diaphragm encountered pressure discontinuities at the edges of sealing glands, but the effects were minor and did not threaten the integrity of the system as a whole. It is 
argued that reinforcement at these locations by chemical treatment or infusion of a harder polymer would completely mitigate these effects.

Using this system, accelerated life testing was performed on carbon-fiber / epoxy laminates. These laminates were composed of four or twelve plies of unwoven biaxial carbon fiber cloth and were cut to form specimens with either symmetric [0/90] or [+45/-45] layups. A diffusion study was performed on samples of the four ply material at $41.3 \mathrm{MPa}$ hydrostatic pressure to determine the temperature dependence of water ingression through Arrhenius methodology. By drawing absorption curves for three different temperatures, the activation energy of water ingression was determined. Using a reference temperature of $3.0^{\circ} \mathrm{C}$ for the sea-floor ocean environment, the acceleration factor representing the ratio of simulated laboratory aging time at $70^{\circ} \mathrm{C}$ to real world exposure time was determined to be $0.64 \mathrm{yr} / \mathrm{day}$.

Using this acceleration factor, specimens for quasi-static in-plane tension and shear and air-blast experiments were aged for periods of 14 and 24 days, simulating 8.90 and 15.3 years of exposure respectively. Compared to an unexposed case, the tensile and shear moduli as well as ultimate tensile and shear strengths and strains did not change significantly with exposure time. This is counter to other studies that aged for similar times without pressure. Yet at the same time, flexural modulus was observed to decrease dramatically by $13.8 \%$ and $20.1 \%$, respectively for the same weathering cases compared to baseline. It is thought that the high hydrostatic pressure during aging closed micro-voids at the fiber-matrix interface and forced water ingression to concentrate in the matrix layers between plies. In this way, the matrix binding the fibers within each ply, which were compressed during aging, were left 
relatively moisture free and thus not degraded, while the matrix between plies, responsible for interlaminar behavior, which flexure is dominated by, was left in a homogeneous, uninterrupted, albeit compressed state able to accept penetrants and thus degrade.

Fixed-fixed beams were subjected to air-blast loading using a shock tube. All beams were seen to deform and recover their original shape elastically and without slip during loading. Although the loadings for each case were of different magnitudes, the similar temporal form of the loading allowed the use of an impulse based normalization technique which considered the ratio of peak out-of-plane displacements of beams relative to the impulse imparted to them. The beams were of similar shape and areal densities and boundary conditions were held constant, and in the impulse domain, loadings were seen to be linear scalings of each other, thus allowing this linear normalization method. When comparing the deflections normalized by this method, differences on the order of about $5 \%$ were observed, which is believed to be within the margin of error of detection by this method. Thus, no significant deviations in blast response were seen, which agrees with the findings from quasi-static in-plane experiments. This is consistent, as the deflection of a fixedfixed beam subjected to out-of-plane loading tends to stress individual plies in tension. Once again, this deviation in degradation from other studies is speculatively explained by the effect of hydrostatic pressure on the concentration of moisture around the fibermatrix interface. Large hydrostatic pressures may close interfacial voids to the point where penetrants cannot ingress and thus degradation is mitigated within the plies. 
In summary, a new system and method for conducting accelerated life testing using sea-water and other corrosive media at high pressures was developed and implemented. The effects of long term exposure to a sea-floor ocean environment on the mechanical behavior of carbon-fiber / epoxy composites were studied through both quasi-static and dynamic experimentation. It is the author's hope that these efforts do well to inform the design of devices for long, trouble-free service in this relatively unexplored frontier and extend the reach of humanity with confidence to depths never before practically considered. 


\section{BIBLIOGRAPHY}

Al-Mazrouee, A., and Singh Raman, R. K. (September 21, 2006). "High Temperature Oxidation of Cr-Mo Steels in the Context of Accelerated Rupture Testing for Creep Life Prediction." ASME. Journal of Pressure Vessel Technology. August 2007; 129(3): 454-459. https://doi.org/10.1115/1.2748826

Aminabhavi, T. M., Thomas, R. W., \& Cassidy, P. E. (1984). Predicting water diffusivity in elastomers. Polymer Engineering \& Science, 24(18), 1417-1420.

ASTM D2000-18, Standard Classification System for Rubber Products in Automotive Applications, ASTM International, West Conshohocken, PA, 2018, Www.astm.org

ASTM D2584-02, Standard Test Method for Ignition Loss of Cured Reinforced Resins, ASTM International, West Conshohocken, PA, 2002, www.astm.org

ASTM D3039 / D3039M-17, Standard Test Method for Tensile Properties of Polymer Matrix Composite Materials, ASTM International, West Conshohocken, PA, 2017, www.astm.org

ASTM D3518 / D3518M-18, Standard Test Method for In-Plane Shear Response of Polymer Matrix Composite Materials by Tensile Test of a $\pm 45^{\circ}$ Laminate, ASTM International, West Conshohocken, PA, 2018, www.astm.org ASTM D7264 / D7264M-15, Standard Test Method for Flexural Properties of Polymer Matrix Composite Materials, ASTM International, West Conshohocken, PA, 2015, www.astm.org BRP Manufacturing, Inc., 2020, “Diaphragm Nitrile Specification Sheet-C500,” Data Sheet, accessed February 4, 2020, http://brpmfg.com/wp- 
content/uploads/2016/08/Nitrile-Nylon-Iserted-Diaphrgam-Sheet-C500-PBWeb-10-14-.pdf

Cartié, D., Davies, P., Peleau, M., Partridge, I. K., The influence of hydrostatic pressure on the interlaminar fracture toughness of carbon/epoxy composites, Composites Part B: Engineering, 37(4-5), 292-300, https://doi.org/10.1016/j.compositesb.2005.12.002.

Cerakote, Inc. 2019. “Cerakote Elite Series Technical Data Sheet,” Data Sheet. Last Revised November 12, 2019.

Chen, S., Xu, H., Duan, H., Hua, M., Wei, L., Shang, H., \& Li, J. (2017). Influence of hydrostatic pressure on water absorption of polyoxymethylene: experiment and molecular dynamics simulation. Polymers for Advanced Technologies, 28(1), 59-65. https://doi.org/10.1002/pat.3858

Crank J. 2nd ed. The Mathematics of Diffusion UK: Oxford University Press; 1975.ISBN-13: 978-019853411

Davies, P., Choqueuse, D., Bigourdan, B., and Chauchot, P. (July 18, 2016). "Composite Cylinders for Deep Sea Applications: An Overview." ASME. Journal of Pressure Vessel Technology. December 2016; 138(6): 060904. https://doi.org/10.1115/1.4033942

Deniz, M., Ozen, M., Ozdemir, O., Karakuzu, R., Icten, B., Environmental effect on fatigue life of glass-epoxy composite pipes subjected to impact loading, Composites Part B: Engineering, 44(1), 2013, 304-312, https://doi.org/10.1016/j.compositesb.2012.05.001. 
Fine, Rana A., Millero, Frank J., "Compressibility of water as a function of temperature and pressure," Journal of Chemical Physics. 59, 5529 (1973); https://doi.org/10.1063/1.167990359

Guo, J. Q., Li, F., Zheng, X. T., Shi, H. C., and Meng, W. Z. (February 5, 2016). "An Accelerated Method for Creep Prediction From Short Term Stress Relaxation Tests." ASME. Journal of Pressure Vessel Technology. June 2016; 138(3): 031401. https://doi.org/10.1115/1.4032109

Gupta, S., Parameswaran, V., Sutton, A., and Shukla, A. Study of dynamic underwater implosion mechanics using digital image correlation. 470 Proceedings of the Royal Society. A. https://doi.org/10.1098/rspa.2014.0576

Hermida, A., "Deflection of Circular Membrane Under Differential Pressure," NASA Tech Briefs, Vol. 22, No. 5 (May 1998), page 78

Humeau, C., \& Davies, P. (2015). Moisture diffusion under hydrostatic pressure in composites, Materials \& Design, 96(July), 19

Khairi N., Rubber as an Engineering Material: Guideline for Users. Hanser Publishers, Munich, 1993.

Kishore, Barpanda, P., \& Kulkarni, S. M. (2005). Compression strength of saline water-exposed epoxy system containing fly ash particles. Journal of Reinforced Plastics and Composites, 24(15), 1567-1576. https://doi.org/10.1177/0731684405050390

Le Gac, P.-Y., Davies, P., \& Choqueuse, D. (2015). Evaluation of Long Term Behaviour of Polymers for Offshore Oil and Gas Applications. Oil \& Gas 
Science and Technology - Revue d'IFP Energies Nouvelles, 70(2), 279-289. https://doi.org/10.2516/

Matos, H., Javier, C., LeBlanc, J., \& Shukla, A. (2018). Underwater nearfield blast performance of hydrothermally degraded carbon-epoxy composite structures. Multiscale and Multidisciplinary Modeling, Experiments and Design, 1(1), 3347. https://doi.org/10.1007/s41939-017-0004-6

Mouritz, A. P., Gellert, E., Burchill, P., \& Challis, K. (2001). Review of advanced composite structures for naval ships and submarines. Composite Structures, 53(1), 21-42.

Nacher, L. S., Amoros, J. E. C., Moya, M. D. S., \& Martinez, J. L. (2007). Mechanical Properties of Polyester Resins in Saline Water Environments. International Journal of Polymer Analysis and Characterization, 12(5), 373-390. https://doi.org/10.1080/10236660701516557

Nicholas, J., Mohamed, M., Dhaliwal, G.S., Anandan, S., Chandrashekhara, K., (2016) Effects of accelerated environmental aging on glass fiber reinforced thermoset polyurethane composites, Composites Part B: Engineering, 94, 370378, https://doi.org/10.1016/j.compositesb.2016.03.059.

Papanicolaou, G. C., Kosmidou, T. V., Vatalis, A. S., \& Delides, C. G. (2006). Water absorption mechanism and some anomalous effects on the mechanical and viscoelastic behavior of an epoxy system. Journal of Applied Polymer Science, 99(4), 1328-1339. https://doi.org/10.1002/app.22095 
Park, S. W., Veazie, D. R., \& Zhou, M. (2000, May). Post-impact aging of FRP composite laminates in the marine environment. In Proceedings of the 14th Engineering Mechanics Conference, Austin, TX.

Pilli, S. P., \& Smith, L. V. (2012). The effect of pressure on moisture diffusion in polymer matrix composites. International Journal of Thermophysics, 33(8-9), 1715-1725. https://doi.org/10.1007/s10765-012-1329-3

Pinto, M., Matos, H., Gupta, S., and Shukla, A. (2016). "Experimental Investigation on Underwater Buckling of Thin-Walled Composite and Metallic Structures." ASME. Journal of Pressure Vessel Technology. December 2016; 138(6): 060905. https://doi.org/10.1115/1.4032703

Pollard, A., Baggott, R., Wostenholm, G. H., Yates, B., \& George, A. P. (1989). Influence of hydrostatic pressure on the moisture absorption of glass fibrereinforced polyester. Journal of Materials Science, 24(5), 1665-1669. https://doi.org/10.1007/BF01105689

Rice, M., \& Ramotowski, T. (2011). Activation energy calculation for the diffusion of water into PR-1590 and pellethane 2103-80AW polyurethanes. NUWC-NPT Technical Memo, 11-062.

Shillings, C., Javier, C., LeBlanc, J., Tilton, C., Corvese, L., \& Shukla, A. (2017). Experimental and computational investigation of the blast response of CarbonEpoxy weathered composite materials. Composites Part B: Engineering, 129, 107-116. https://doi.org/10.1016/j.compositesb.2017.07.023 
Siriruk, A., Penumadu, D., \& Weitsman, Y. J. (2009). Effect of sea environment on interfacial delamination behavior of polymeric sandwich structures. Composites Science and Technology, 69(6), 821-828.

Tucker, W. C., \& Brown, R. (1989). Moisture Absorption of Graphite / Polymer Composites Under 2000 Feet of Seawater, Journal of Composite Materials, 23(8), 787-797 https://doi.org/10.1177\%2F002199838902300802

Tucker, W., Lee, S., \& Rockett, T. (1993). The effects of pressure on water transport in polymers. Journal of Composite Materials, 27(8), 756-763. Retrieved from http://jcm.sagepub.com/content/27/8/756.

Wang, E., Wright, J., Shukla, A. (2011). "Analytical and experimental study on the fluid structure interaction during air blast loading," Journal of Applied Physics, 110(11), https://doi.org/10.1063/1.3662948

Xu, L., Krishnan, A., Ning, H., Vaidya, U., (2012) A seawater tank approach to evaluate the dynamic failure and durability of E-glass/vinyl ester marine composites, Composites Part B: Engineering, 43(5), pp. 2480-2486, https://doi.org/10.1016/j.compositesb.2011.08.039.

Zuo, M., Chiovelli, S., and Nonaka, Y. (2000). "Fitting Creep-Rupture Life Distribution Using Accelerated Life Testing Data ." ASME. Journal of Pressure Vessel Technology. November 2000; 122(4): 482-487. https://doi.org/10.1115/1.1310164 